Environmental Molecular Sciences Laboratory

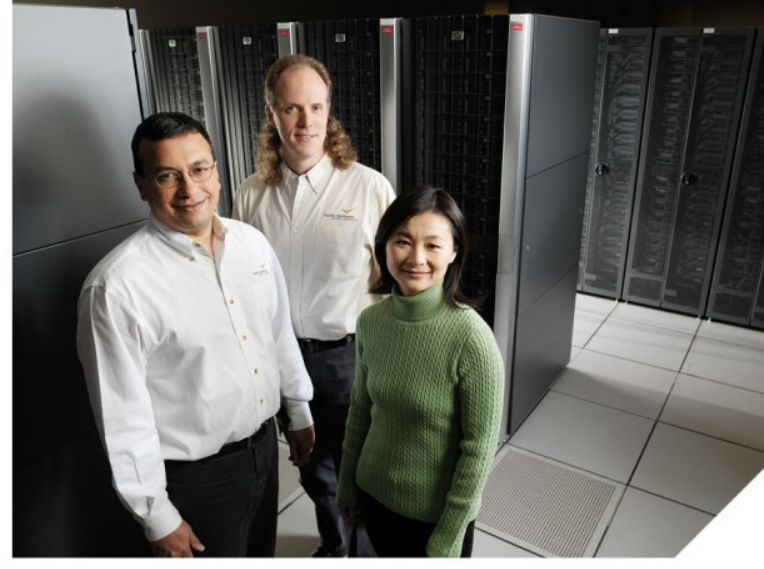

\title{
EMSL Quarterly
} Highlights Report

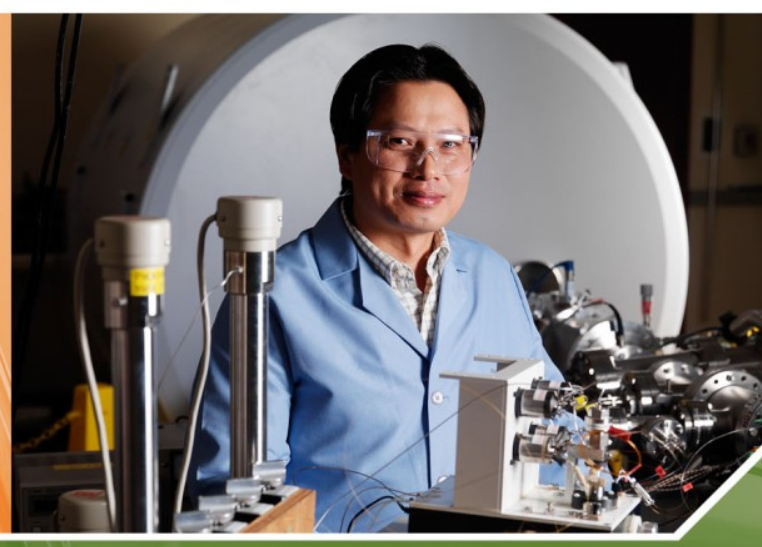

Second Quarter, Fiscal Year 2010

January 1, 2010 through March 31, 2010
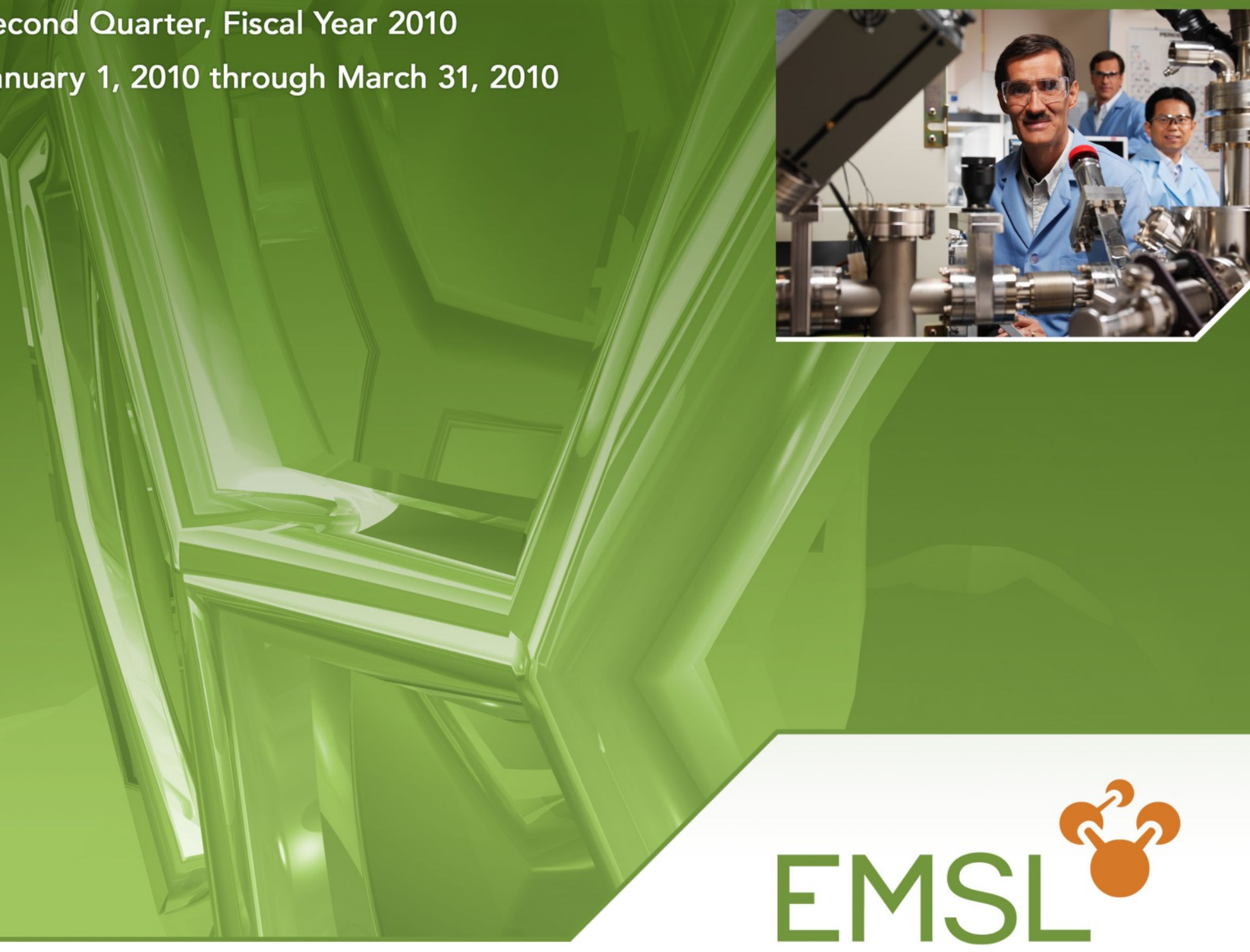


\title{
DISCLAIMER
}

This report was prepared as an account of work sponsored by an agency of the United States Government. Neither the United States Government nor any agency thereof, nor Battelle Memorial Institute, nor any of their employees, makes any warranty, express or implied, or assumes any legal liability or responsibility for the accuracy, completeness, or usefulness of any information, apparatus, product, or process disclosed, or represents that its use would not infringe privately owned rights. Reference herein to any specific commercial product, process, or service by trade name, trademark, manufacturer, or otherwise does not necessarily constitute or imply its endorsement, recommendation, or favoring by the United States Government or any agency thereof, or Battelle Memorial Institute. The views and opinions of authors expressed herein do not necessarily state or reflect those of the United States Government or any agency thereof.

\author{
PACIFIC NORTHWEST NATIONAL LABORATORY \\ operated by \\ BATTELLE \\ for the \\ UNITED STATES DEPARTMENT OF ENERGY \\ under Contract DE-AC05-76RL01830
}

\author{
Printed in the United States of America \\ Available to DOE and DOE contractors from the \\ Office of Scientific and Technical Information, \\ P.O. Box 62, Oak Ridge, TN 37831-0062; \\ ph: (865) 576-8401 \\ fax: $(865) 576-5728$ \\ email: reports@adonis.osti.gov

\begin{abstract}
Available to the public from the National Technical Information Service, ph: (800) 553-6847 fax: (703) 605-6900 email: orders@ntis.fedworld.gov online ordering: http://www.ntis.gov/ordering.htm
\end{abstract} \\ U.S. Department of Commerce, 5285 Port Royal Rd., Springfield, VA 22161
}




\title{
EMSL Quarterly Highlights Report Second Quarter, Fiscal Year 2010 (January 1, 2010 through March 31, 2010)
}

\author{
SA West \\ MA Showalter \\ KL Manke \\ RR Carper \\ JG Wiley \\ MT Beckman
}

April 2010

Prepared for the U.S. Department of Energy's Office of Biological and Environmental Research under Contract DE-AC05-76RL01830

Pacific Northwest National Laboratory

Richland, Washington 99352 



\section{Executive Summary}

The Environmental Molecular Sciences Laboratory (EMSL) is a U.S. Department of Energy (DOE) national scientific user facility located at Pacific Northwest National Laboratory (PNNL) in Richland, Washington. EMSL is operated by PNNL for the DOE-Office of Biological and Environmental Research. At one location, EMSL offers a comprehensive array of leading-edge resources and expertise. Access to the instrumentation and expertise is obtained on a peer-reviewed proposal basis. Staff members work with researchers to expedite access to these capabilities. The EMSL Quarterly Highlights Report documents current research and activities of EMSL staff and users. 



\section{Acronyms and Abbreviations}

$\begin{array}{ll}\text { DOE } & \text { U.S. Department of Defense } \\ \text { EMSL } & \text { Environmental Molecular Sciences Laboratory } \\ \text { NIH } & \text { National Institutes of Health } \\ \text { NMR } & \text { nuclear magnetic resonance } \\ \text { OMC } & \text { outer-membrane cytochrome } \\ \text { ORF } & \text { open reading frame } \\ \text { PNNL } & \text { Pacific Northwest National Laboratory } \\ \text { STM } & \text { scanning tunneling microscope }\end{array}$





\section{Contents}

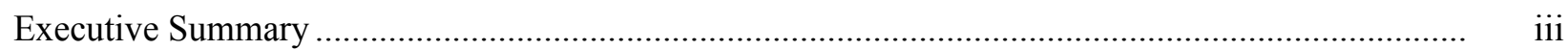

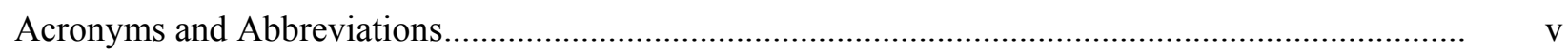

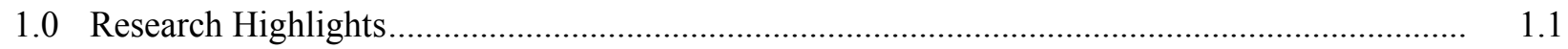

1.1 Biological Interactions and Dynamics .................................................................. 1.1

1.2 Geochemistry/Biogeochemistry and Subsurface Science ............................................ 1.7

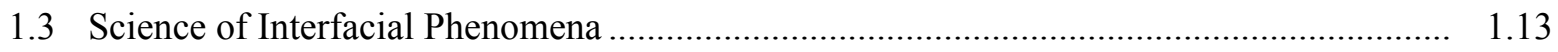

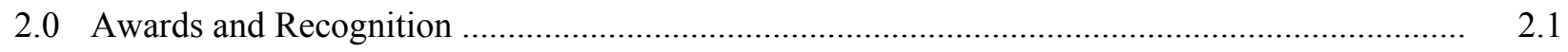

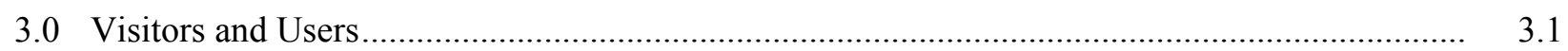

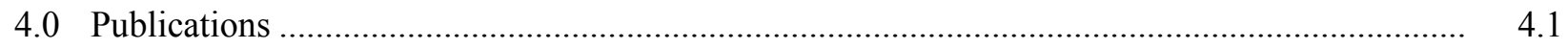

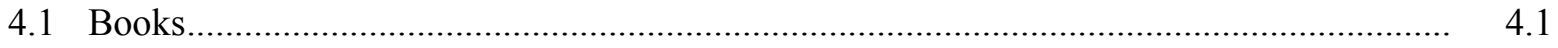

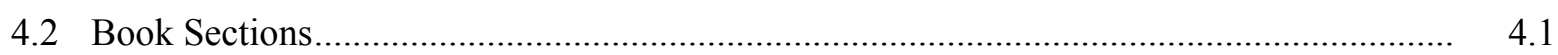

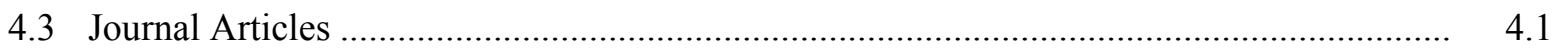




\section{Figures}

Figure 1.1. Using resources at EMSL, scientists observed ERK cycling in and out of the cell nucleus (bright green in center of some cells) in healthy, cultured breast cells.

Figure 1.2. Using EMSL's capabilities, researchers used a pioneering four-step approach to map the E. coli genome.

Figure 1.3. High-field, low-temperature NMR at EMSL harvests unprecedented characterization of metalloproteins, such as azurin.

Figure 1.4. Organization of 10 novel open reading frames (ORFs) overlapping predicted genes in P. fluorescens Pf0-1. The novel ORFs are colored red and indicated by "nov" (or n7 for nov7), while predicted Pf0-1 genes are colored blue and labeled with the Pf101 number of the locus tag corresponding to each in the Pf0-1 GenBank entry. Three forward (numbered 1-3) and three reverse (numbered 4-6) reading frames are shown. Parallel diagonal lines indicate that the complete ORF is not shown to scale.

Figure 1.5. Scanning electron micrographs of synthetic tabular hematite powder shown before (blue) and after (gold) a 24-hour reaction in $1 \mathrm{mM} \mathrm{FeCl}_{2}+10 \mathrm{mM}$ oxalic acid at $\mathrm{pH} 2.10$, temperature $348 \mathrm{~K}$. The deposition of pyramidal hematite island overgrowths is seen after the reaction.

Figure 1.6. Photomicrographs of Shewanella oneidensis MR-1 wild-type cells (blue) cultured aerobically on $\mathrm{Fe}(\mathrm{III})$-citrate plates. Epifluorescence micrographs demonstrate specific labeling of the cell surface with antibodies against (A) MtrC or (B) OmcA (green).

1.8

Figure 1.7. An illustration of the cluster specified in NMR parameter computations of $\mathrm{UO}_{2} \mathrm{CO}_{3}$. Atom color scheme: $\mathrm{U}=$ gold, $\mathrm{C}=$ gray, $\mathrm{O}=$ red, and $\mathrm{N}=$ blue.

Figure 1.8. Using EMSL spectroscopy resources, scientists discovered the reactions converting uranium from soluble to insoluble forms.

Figure 1.9. Using powerful X-ray photoelectron spectrometry on both cryogenic/hydrated and noncryogenic samples, scientists identified satellite structures on the spectra that indicated the presence of uranium $(\mathrm{V})$.

Figure 1.10. Using resources at EMSL, scientists obtained parameter-free first principles simulations of a high spin $3 \mathrm{~d}^{5} \mathrm{Fe}^{3+}$ ion (colorful, larger spheres) surrounded by 64 waters (smaller red and white structures) at 30 ps and $300 \mathrm{~K}$.

Figure 1.11. Specialists in molecular theory at EMSL achieved a breakthrough in calculating properties and behavior of molecules in chemical reactions.

Figure 1.12. An illustration of SBA-16's spherical "cages," complete with metal nanoparticles protected within the mesostructures.

Figure 1.13. A grating, written on a gold cone using a focused ion beam, leads to surface plasmon coupling of incident laser light with near-infrared wavelength. The surface plasmon polaritons (SPP) effectively help focus the light, which, when remitted from the gold nano-tip, has a radius less than or equal to $15 \mathrm{~nm}$. The graph indicates the lateral optical scan used to measure spatial field confinement and size of the emitter at the apex. In this case, the $20 \mathrm{~nm}$ width demonstrates the highly confined light source. 


\subsection{Research Highlights}

\subsection{Biological Interactions and Dynamics}

\section{Rapid and Sustained Nuclear-Cytoplasmic ERK Oscillations Induced by Epidermal Growth Factor}

\section{Harish Shankaran, ${ }^{(a)}$ Danielle L. Ippolito,${ }^{(a)}$ William B. Chrisler, ${ }^{(a)}$ Haluk Resat, ${ }^{(a)}$ Nikki Bollinger,${ }^{(a)}$ Lee K. Opresko, ${ }^{\text {(a) }}$ and H. Steven Wiley ${ }^{(b)}$}

(a) Pacific Northwest National Laboratory, Richland, Washington

(b) EMSL, Richland, Washington

For the first time, scientists have proven that a vital protein controlling cellular proliferation, ERK, oscillates in and out of the nucleus of human breast cells. Researchers from PNNL, led by EMSL Lead Scientist for Biology, Steve Wiley, observed sustained oscillations of ERK between the nucleus and cytoplasm. By integrating multiple scientific disciplines, instruments, and standard computational packages at EMSL, the team proved the long-suspected oscillations.

Understanding ERK's role in regulating cell proliferation is vital to research designing antiproliferative drugs to treat cancer and other diseases.

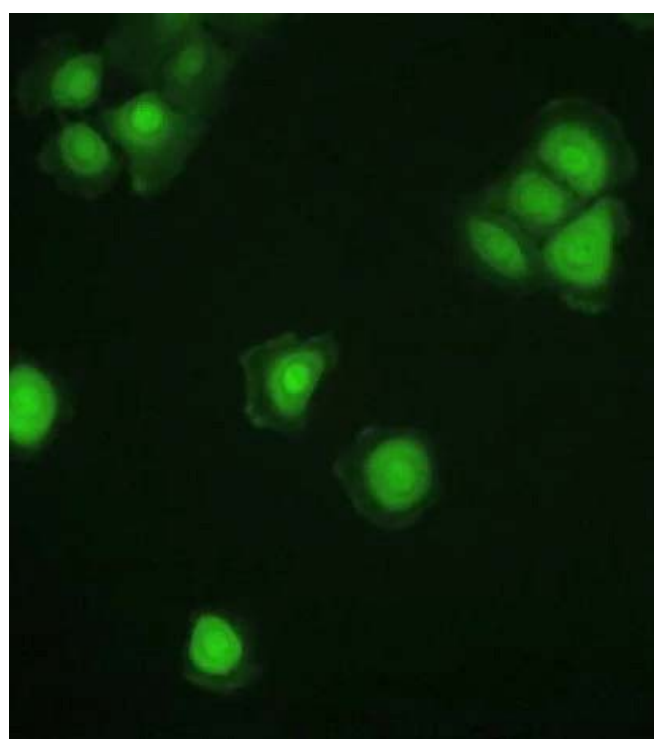

Figure 1.1. Using resources at EMSL, scientists observed ERK cycling in and out of the cell nucleus (bright green in center of some cells) in healthy, cultured breast cells. See the video on the EMSL website (http://www.emsl.pnl.gov).

Each cycle took approximately 15 minutes. The oscillations were persistent, with more than 45 cycles observed. The oscillations were also independent of the phase of the cell. With the quantitative data from this study, modeling experts can constrain mathematical models to obtain more accurate simulations and obtain better behavioral predictions of ERK activity.

Although the ERK pathway has a central role in how cells respond to growth factors, its regulatory structure and dynamics are not completely understood. This characterization of single-cell ERK dynamics provides experimentally backed constraints for modeling the regulatory structure of the signaling cascade and other behaviors. This research is part of EMSL's ongoing efforts in predicting biological functions from molecular and chemical data. 
This research was published in Molecular Systems Biology and quickly became the top download on the journal's website in December 2009.

Reference: Shankaran H, DL Ippolito, WB Chrisler, H Resat, N Bollinger, LK Opresko, and HS Wiley. 2009. "Rapid and Sustained Nuclear-Cytoplasmic ERK Oscillations Induced by Epidermal Growth Factor." Molecular Systems Biology 5(322). DOI:10.1038/msb.2009.90.

Funding: PNNL's Biomolecular Systems Initiative and the National Institutes of Health (NIH).

\section{The Transcription Unit Architecture of the Escherichia coli Genome}

\section{Byung-Kwan Cho ${ }^{(a)}$ Karsten Zengler,${ }^{(a)}$ Yu Qiu, ${ }^{(a)}$ Young Seoub Park,,${ }^{(a)}$ Eric M. Knight, ${ }^{(a)}$ Christian L. Barrett, ${ }^{(a)}$ Yuan Gao, ${ }^{(b)}$ and Bernhard Ø Palsson ${ }^{(a)}$}

(a) University of California, San Diego, La Jolla, California

(b) Virginia Commonwealth University, Richmond, Virginia

Understanding how DNA-encoded information is organized to produce protein-mediated processes will unlock breakthroughs in energy production, environmental protection, and medical science. To augment current knowledge of how genetic information is controlled at the molecular level, researchers have developed and applied a new systems-level approach for generating the comprehensive transcription unit architecture of Escherichia coli K-12 MG1655. Integrating multiple "omics" measurements, including proteomics data obtained at EMSL, a team of researchers from the University of California-San Diego and Virginia Commonwealth University identified roughly five times more transcription units of E. coli than previously known and improved translation start site mapping over earlier annotations. The team's research was featured on the November 2009 cover of Nature Biotechnology.

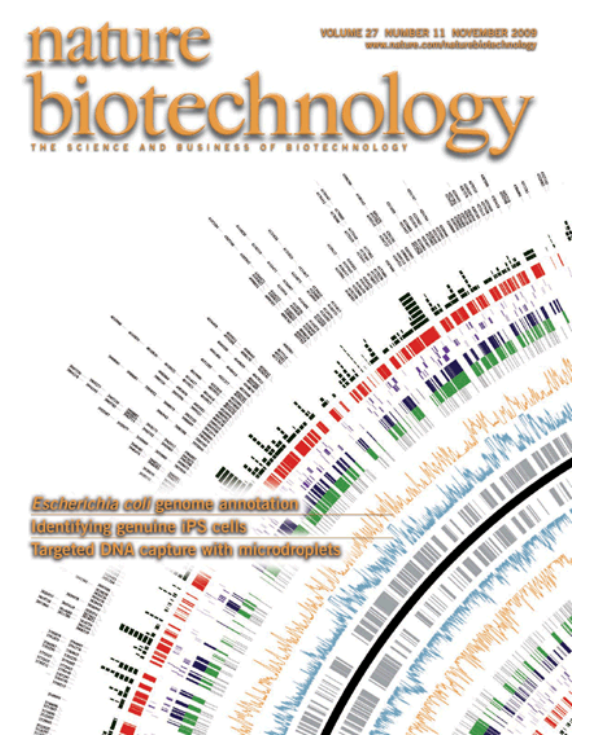

Figure 1.2. Using EMSL's capabilities, researchers used a pioneering four-step approach to map the E. coli genome. This cover is printed with permission from Nature C2010.

To define the transcription units of $E$. coli and shed light on its genome-wide organizational structure, researchers applied a pioneering, four-step approach to map genetic information to protein function: 1) RNA polymerase binding assays helped the team identify promoters, 2) microarrays revealed gene expression profiles under various growth conditions, 3 ) 
a new sequencing method identified transcriptional start sites, and 4) proteomics data were used to determine translational start and stop sites. The proteomics data, obtained with high-throughput mass spectrometry capabilities at EMSL, both improved and validated data from previous studies - the team observed that only 64 percent of translation start sites were accurately identified by annotation tools, but greater than 99 percent of translation stop sites were matched correctly. In total, the researchers' integrated process was able to identify 4,661 transcription units-far more than the 875 that had previously been identified through experiments. This new wealth of data for E. coli has great potential to allow researchers to manipulate the bacterium's functions in valuable ways, such as for assisting in bioremediation, optimizing industrial chemical production, and protecting human health.

The team's integrated systems-level approach, which connects measurements made across the bacterium's genome, transcriptome, and proteome, is broadly applicable to many organisms. The resulting knowledge of E. coli K-12 MG1655 accelerates the construction of its complete transcriptional and translational regulatory network - opening the door to unprecedented understanding of complex biological functions. Moreover, this work supports EMSL's goal to predict biological functions from molecular and chemical data.

Understanding genetic information flow can lead to significant biotechnology advancements. Armed with new knowledge, researchers may be able to modify E. coli to convert biomass into biofuels efficiently, manipulate $E$. coli to consume environmental contaminants, or develop drug therapies that inhibit bacterial infection without damaging the host.

Reference: Cho BK, K Zengler, Y Qiu, YS Park, EM Knight, CL Barrett, Y Gao, and BO Palsson. 2009. "The Transcription Unit Architecture of the Escherichia coli Genome." Nature Biotechnology 27(11):1043-1051. DOI: 10.1038/nbt.1582.

Funding: NIH and DOE-Office of Science

Quadrupolar Metal Nuclides in Bioinorganic Chemistry: Solid-State NMR Studies

\section{Andrew Lipton, ${ }^{(a)}$ Paul Ellis, ${ }^{(b)}$ and Tatyana E. Polenova ${ }^{(c)}$}

(a) PNNL, Richland, Washington

(b) EMSL, Richland, Washington

(c) University of Delaware, Newark, Delaware

Technology without integration cannot reach its full potential to enable cutting-edge science. In the case of studying the structures and functions of metalloproteins-proteins that include metal ions for their chemical properties-researchers from PNNL and the University of Delaware have integrated state-of-the-art experimental and theoretical chemistry capabilities at EMSL. The result is an atomic-level characterization of the metal centers within metalloproteins, the sites at which organic and inorganic molecules bind together to play a specific role in an organism. Thorough understanding of metalloproteins may set the stage for biotechnology breakthroughs, such as the development of synthetic proteins that support biofuel production, environmental protection, or human health. These scientists have prominently shared their procedures with the research community in both the Encyclopedia of Magnetic Resonance and the forthcoming Handbook on Biopolymers.

The advent of high-field nuclear magnetic resonance (NMR) studies has broken boundaries in molecular- and atomiclevel measurement, and, with EMSL housing NMR spectrometers with $1 \mathrm{H}$ frequencies up to $900 \mathrm{MHz}$, there is no lack of high-field capability. However, because of the extremely poor sensitivity of quadrupolar nuclides in biological systems, applying high-field NMR methods to metalloproteins has been arduous and largely unexplored. The team has optimized 
methods to overcome this challenge, determining that solid-state NMR at cryogenic temperatures, when combined with advanced quantum chemistry calculations, can yield intricate, unprecedented models of metal-site geometry and electronic structure within metalloproteins.

This research provides a foundational discussion of integrating high-field NMR with quantum molecular theory to reveal the active-site electronic structures of metalloproteins. By sharing lessons learned while studying several quadrupolar nuclides in different metalloproteins, this teaching resource allows bioinorganic chemists to obtain better results while saving time and money. This work supports EMSL's goals to 1) predict biological functions from molecular and chemical data and 2) rapidly link theory and experiment.

Understanding the structures of metalloproteins can help elucidate their functions, which, in turn, can be synthesized or directed to support energy production, environmental remediation, and human health.

References: Lipton AS, PD Ellis, and TE Polenova. 2009. "Quadrupolar Metal Nuclides in Bioinorganic Chemistry: Solid-State NMR Studies.” In Encyclopedia of Magnetic Resonance. John Wiley \& Sons, Ltd., Hoboken, New Jersey. (Also forthcoming in Handbook on Biopolymers, eds. TE Polenova and AE McDermott. John Wiley \& Sons, Ltd., Hoboken, New Jersey.)

Funding: NIH and the National Science Foundation

Low Temperature ${ }^{65} \mathrm{Cu}$ NMR Spectroscopy of the $\mathrm{Cu}^{+}$Site in Azurin

Andrew S. Lipton, ${ }^{(a)}$ Robert W. Heck, ${ }^{(a)}$ Wibe A. de Jong, ${ }^{(a)}$ Amy R. Gao, ${ }^{(a)}$ Xiongjian Wu, ${ }^{(b)}$ Adrienne Roehrich, ${ }^{(b)}$ Gerard S. Harbison, ${ }^{(b)}$ and Paul D. Ellis ${ }^{(a)}$

(a) PNNL, Richland, Washington

(b) University of Nebraska, Lincoln, Nebraska

Metalloproteins, such as copper-containing azurin, play a major role in catalyzing electron transfer in cellular reactions. Understanding how their structure relates to function can give rise to advances in biotechnology and medicine. To accurately characterize the electrostatics around azurin's metal center, a team of researchers from PNNL and the University of Nebraska at Lincoln obtained the first high-field NMR signal of a copper site in a copper protein.

Using NMR to study copper-containing proteins, a technique previously ignored because copper's large nuclear quadrupole interactions produce weak NMR signals, was made possible by integrating 800-MHz NMR spectroscopy and the Chinook supercomputer, both housed at EMSL. In fact, this combination of tools turned azurin's quadrupolar nature into an advantage as the researchers gained an "exquisitely sensitive measure of the electron density around the nuclear site," revealing previously unknown details about the electronic structure and environment of azurin's copper center.

The advent of high-magnetic fields and theoretical supercomputing capabilities allow opportunities for scientists to perform previously impossible experiments and validate the results with powerful calculations and models. The team used these advances to fill gaps in azurin's data pool, finding informative spin-lattice relaxation of samples unexpectedly efficient, even when using an 800-MHz NMR. Data were then reproduced using theoretical calculations, confirming details of the electronic structure. In addition to yielding new information on azurin, this study helps demonstrate that high-field, low-temperature NMR, when combined with electronic structure theory, provides a detailed and precise probe of metal nuclei in metalloproteins. 
Developing the novel ability to use high-field NMR to characterize the electronic structure of metalloproteins containing metals such as ${ }^{65} \mathrm{Cu}$ provides a powerful new tool that advances the field of bioinorganic chemistry (the study of how living systems use nonliving elements to perform fundamental biological functions). The team's strategy broadens the arena of NMR samples and is applicable to any diamagnetic metalloprotein. This work supports EMSL's goals to 1) predict biological functions from molecular and chemical data and 2) rapidly link theory and experiment.

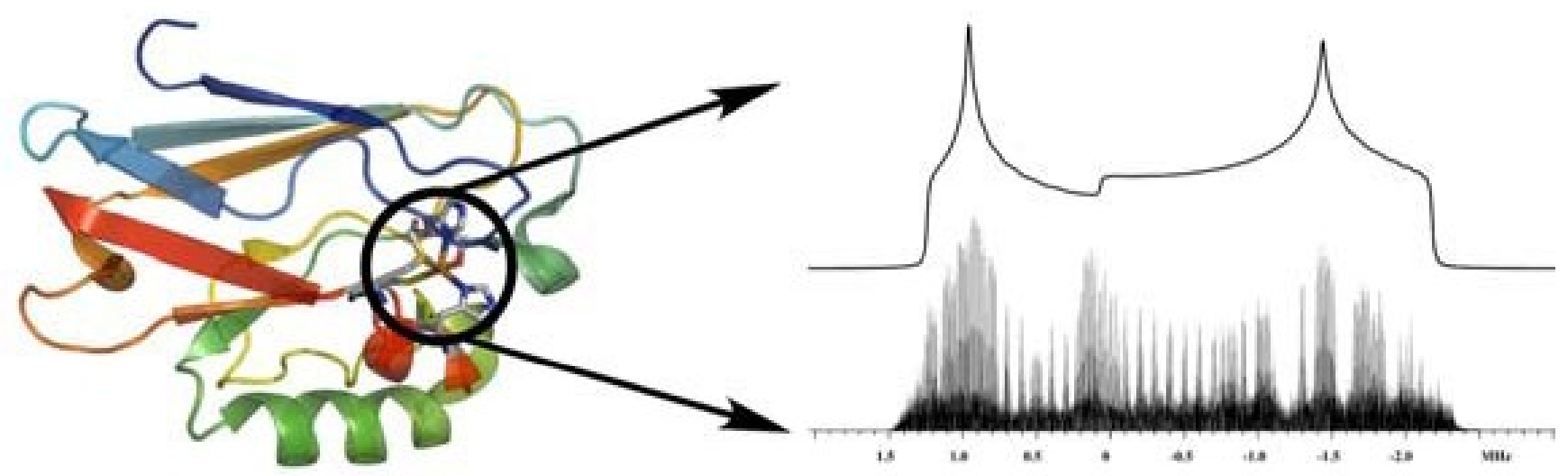

Figure 1.3. High-field, low-temperature NMR at EMSL harvests unprecedented characterization of metalloproteins, such as azurin.

Reference: Lipton AS, RW Heck, WA de Jong, AR Gao, X Wu, A Roehrich, GS Harbison, and PD Ellis. 2009. "Low Temperature ${ }^{65} \mathrm{Cu}$ NMR Spectroscopy of the $\mathrm{Cu}^{+}$Site in Azurin." Journal of the American Chemical Society 131(39):13992-13999. DOI: 10.1021/ja901308v.

Funding: NIH and DOE-Office of Science

Proteomic Detection of Non-Annotated Protein-Coding Genes in Pseudomonas fluorescens Pf0-1

\section{Kim Wook, ${ }^{(a)}$ Mark W. Silby, ${ }^{(a)}$ Sam Purvine, ${ }^{(b)}$ Julie S. Nicoll, ${ }^{(a)}$ Kim K. Hixson, ${ }^{(b)}$ Matt E. Monroe, ${ }^{(b)}$ Carrie D. Nicora, ${ }^{(b)}$ Mary Lipton, ${ }^{(b)}$, and Stuart Levy ${ }^{(a)}$}

(a) Tufts University, Medford, Massachusetts

(b) PNNL, Richland, Washington

To test whether bacteria might be packing genes more tightly than previously thought, scientists at PNNL and Tufts University compared the proteins made by a bacterial species with what is known about its genome. They chose Pseudomonas fluorescens, Gram-negative, rod-shaped bacteria that inhabit soil, plants, and water surfaces. They used ultra-high-pressure reversed-phase high performance liquid chromatography coupled to an ion trap mass spectrometer at EMSL and found 16 genes for proteins not previously mapped to the P. fluorescens genome. This work shows tools currently used to identify the complete set of genes and proteins in organisms are insufficient. Advances in the tool set and the resulting gains in knowledge could lead to insights in evolutionary biology.

In microbial genomes, genes are typically depicted as linear series of separate regulatory and coding regions. This leads to the assumption that annotations conducted via computer to predict such arrangements completely describe the coding capacity of bacterial genomes. 
However, more complex organisms, such as plants and animals, pack their genes into their DNA very densely. One common packing trick is to code genes on both strands of the DNA, allowing the genes to overlap along the chromosome. Bacterial genes previously shown to reside on the second, or anti-sense, strand overlap just a little (for example, a few dozen DNA bases). Less than a handful of genes overlap completely.

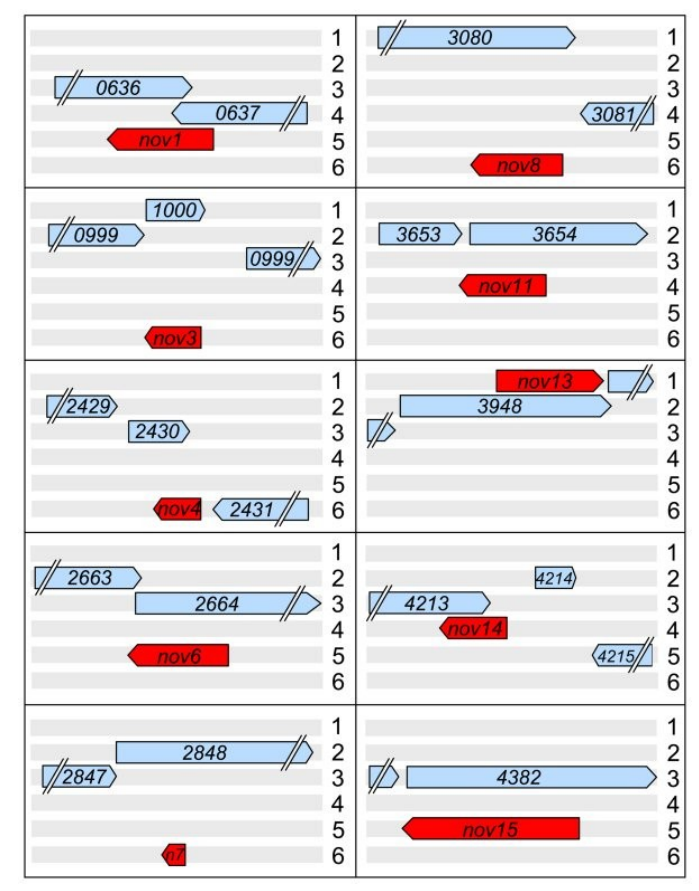

Figure 1.4. Organization of 10 novel open reading frames (ORFs) overlapping predicted genes in P. fluorescens Pf0-1. The novel ORFs are colored red and indicated by "nov" (or n7 for nov7), while predicted Pf0-1 genes are colored blue and labeled with the Pfl01 number of the locus tag corresponding to each in the Pf0-1 GenBank entry. Three forward (numbered 1-3) and three reverse (numbered 4-6) reading frames are shown. Parallel diagonal lines indicate that the complete ORF is not shown to scale.

Using all of the information from a 6-frame translation of the bacterial genome, the team identified as many proteins made by $P$. fluorescens as their instruments would allow and deduced the gene sequence needed to create those proteins. Then, they compared the deduced genes to the genes found by the annotation of the genome.

The team subsequently analyzed coding sequences, reading frames, and comparative alignments and found 16 genes for proteins not previously mapped to the $P$. fluorescens genome. The researchers also found nine previously unknown genes coded on the anti-sense DNA strand. However, unlike other anti-sense genes found in bacteria, these genes overlapped other ones on the sense strand completely or nearly. This suggests that researchers have underestimated how often bacteria pack genes by overlapping them.

The results suggest that the cues researchers use to identify genes by sequence in a stretch of DNA have not all been identified. The 16 newly identified genes improve the quality of the Pf0-1 genome annotation, and the detection of antisense protein-coding genes indicates the underappreciated complexity of bacterial genome organization.

Thus, while current identification tools are insufficient, this work will contribute to a more comprehensive understanding of how the genomic blueprint within bacteria translates into functioning proteins that converge into a living organism, which could influence new insights in evolutionary biology. 
Reference: Wook K, MW Silby, SO Purvine, JS Nicoll, KK Hixson, ME Monroe, CD Nicora, MS Lipton, and SB Levy. 2009. "Proteomic Detection of Non-Annotated Protein-Coding Genes in Pseudomonas fluorescens Pf0-1." PLoS ONE 4(12):e8455. DOI: 10.1371/journal.pone.0008455.

Funding: DOE-Office of Biological and Environmental Research's Genomics Science Program.

\subsection{Geochemistry/Biogeochemistry and Subsurface Science}

\section{Connecting Observations of Hematite $\left(\alpha-\mathrm{Fe}_{2} \mathrm{O}_{3}\right)$ Growth Catalyzed by $\mathrm{Fe}(\mathrm{II})$}

\section{Kevin M. Rosso, ${ }^{(a)}$ Svetlana V. Yanina, ${ }^{(a)}$ Christopher A. Gorski, ${ }^{(b)}$ Philip Larese-Casanova, ${ }^{(c)}$ and Michelle M. Scherer ${ }^{(b)}$}

(a) PNNL, Richland, Washington

(b) University of Iowa, Iowa City, Iowa

(c) Yale University, New Haven, Connecticut

Understanding subsurface processes, such as the uptake and release of technetium and other redox-active contaminants at the molecular level, will play a major role in the future of environmental cleanup and pollution prevention. To elucidate one of the influential reactions involved in these processes-electron and atom exchange between aqueous $\mathrm{Fe}(I I)$ and structural $\mathrm{Fe}(I I I)$ in minerals-researchers from PNNL, the University of Iowa, and Yale University collaborated to connect previous, separate studies on this topic. To make this connection, the team used X-ray diffraction and scanning electron microscopy tools at EMSL and designed experiments that used novel measurement approaches in one of the previous studies to characterize reaction products grown under the conditions of the other study.

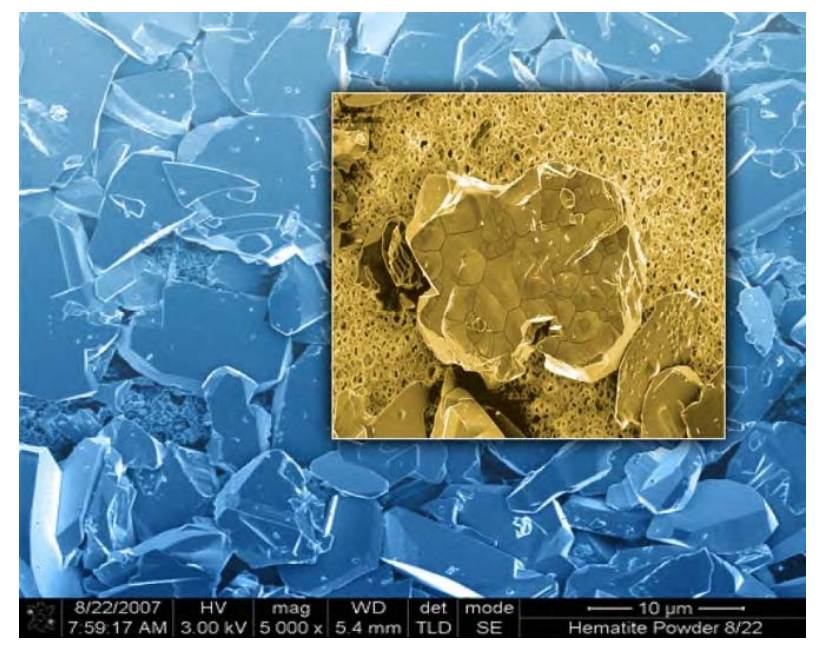

Figure 1.5. Scanning electron micrographs of synthetic tabular hematite powder shown before (blue) and after (gold) a 24-hour reaction in $1 \mathrm{mM} \mathrm{FeCl}_{2}+10 \mathrm{mM}$ oxalic acid at $\mathrm{pH} 2.10$, temperature $348 \mathrm{~K}$. The deposition of pyramidal hematite island overgrowths is seen after the reaction.

Electron transfer among different chemical states and phases of iron has an impact on the makeup and movement of environmental pollutants, including byproducts of nuclear energy production. Converting pollutants into less dangerous forms and reducing their mobility underground protects ecosystems and humans from harmful contact. 
Reference: Rosso KM, S Yanina, CA Gorski, P Larese-Casanova, and M Scherer. 2010. "Connecting Observations of Hematite $\left(\alpha-\mathrm{Fe}_{2} \mathrm{O}_{3}\right)$ Growth Catalyzed by Fe(II).” Environmental Science \& Technology 44(1):61-67. DOI: $10.1021 / \mathrm{es} 901882 \mathrm{a}$.

Funding: DOE-Office of Biological and Environmental Research's Geosciences Program and a Nanoscale Interdisciplinary Research Team (NIRT) grant from the National Science Foundation NIRT

\section{Role of Outer-Membrane Cytochromes MtrC and OmcA in the Biomineralization of Ferrihydrite by Shewanella} oneidensis $M R-1$

\section{Reardon, ${ }^{(a)}$ AC Dohnalkova, ${ }^{(a)}$ P Nachimuthu, ${ }^{(a)}$ DW Kennedy, ${ }^{(a)}$ DA Saffarini, ${ }^{(b)}$ BW Arey, ${ }^{(a)}$ L Shi,,${ }^{(a)}$ Z Wang,${ }^{(a)}$ D Moore,${ }^{(a)}$ JS McLean, ${ }^{(a)}$ D Moyles,${ }^{(c)}$ JM Zachara,${ }^{(a)}$ JK Fredrickson, ${ }^{(a)}$ and AS Baeliaev ${ }^{(a)}$}

(a) PNNL, Richland, Washington

(b) University of Wisconsin, Milwaukee, Wisconsin

(c) University of Guelph, Guelph, Ontario, Canada

As part of a Biogeochemistry Grand Challenge sponsored by EMSL, scientists have made significant progress toward understanding electron exchange at the interface between microbes and minerals. A team from PNNL; the University of Wisconsin, Milwaukee; and the University of Guelph have further improved this understanding by discovering that outermembrane cytochromes (OMCs) MtrC and OmcA of the metal-reducing bacterium Shewanella oneidensis MR-1 are key to transforming ferrihydrite. Along with ongoing research, this work will allow researchers to understand interactions fundamental to contaminant migration, water quality, and soil fertility and to trace metal availability.
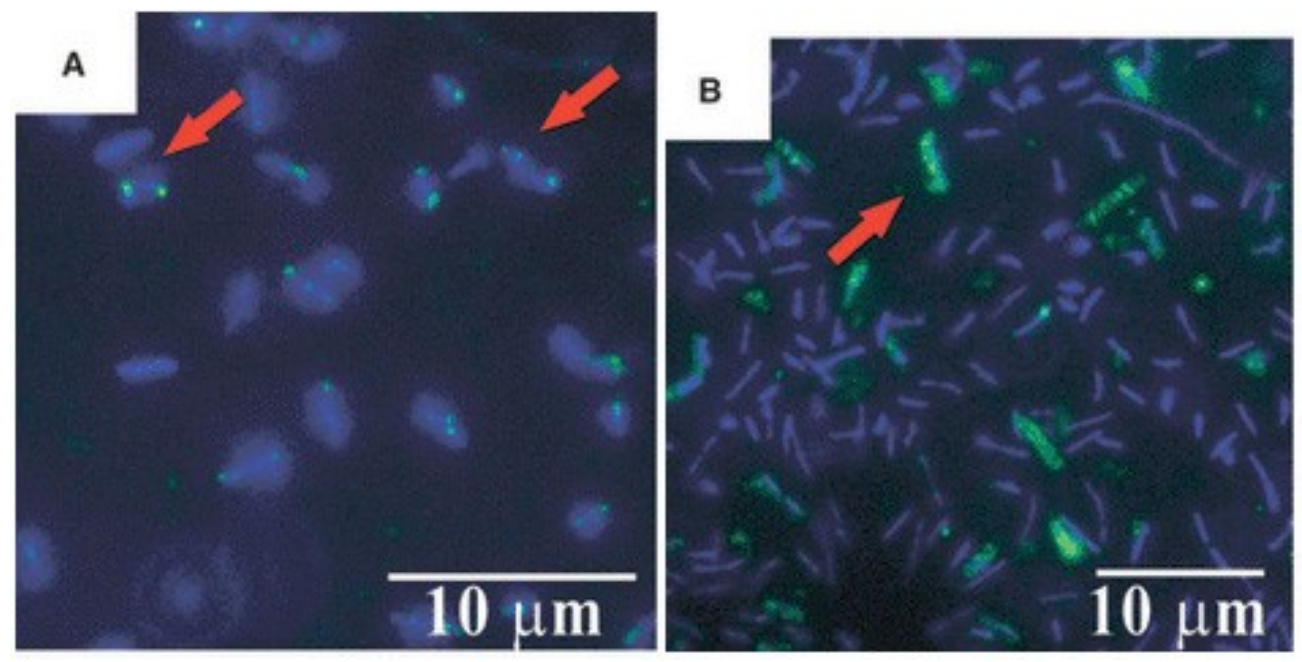

Figure 1.6. Photomicrographs of Shewanella oneidensis MR-1 wild-type cells (blue) cultured aerobically on Fe(III)citrate plates. Epifluorescence micrographs demonstrate specific labeling of the cell surface with antibodies against (A) MtrC or (B) OmcA (green).

Using a suite of microscopic, spectroscopic, and biochemical techniques, the scientists analyzed purified recombinant proteins and investigated genetic mutants unable to produce the OMCs. They demonstrated that both cytochromes undergo rapid electron exchange with ferrihydrite in vitro, with MtrC displaying faster transfer rates than OmcA. Immunomicroscopy with cytochrome-specific antibodies revealed that MtrC collocalizes with iron solids on the cell surface, while OmcA is distributed more diffusely over the cell surface. In the absence of both MtrC and OmcA, the cells' ability to reduce ferrihydrite was significantly hindered, and no mineral transformation products were detected. This study 
demonstrates that at least one of the two cytochromes is required for ferrihydrite reduction and biotransformation. This research was published in Geobiology.

Microbe-mineral interactions are central to biogeochemistry and the fundamental element cycling processes shaping earth's geology. A grand challenge of geomicrobiology is to understand mechanistically the electron transfer processes driving reductive transformations at the microbe-mineral interface. This has proven to be an exceptionally difficult region to probe experimentally. Many mechanisms for extracellular electron transfer to solids by metal-reducing bacteria such as Shewanella have been proposed, but the pathways are poorly understood and few quantitative relationships are established. Collectively, these results highlight the OMCs' importance in reductive transformation of ferrihydrite and support the role of direct electron transfer from OMCs at the cell surface to the mineral. This is part of EMSL's ongoing work in predicting biological functions from molecular and chemical data.

Microorganisms such as $S$. oneidensis MR-1 exchange electrons with minerals in soil, sediment, and subsurface material. These interactions impact processes such as the reduction and stabilization of contaminants in groundwater. Ongoing research will allow scientists to understand this most basic earth-life interaction, which is fundamental to contaminant migration, water quality, soil fertility, and trace metal availability.

Reference: Reardon CL, A Dohnalkova, P Nachimuthu, DW Kennedy, D Saffarini, BW Arey, L Shi, Z Wang, DA Moore, JS Mclean, DM Moyles, MJ Marshall, JM Zachara, JK Fredrickson, and AS Beliaev. 2010. "Role of Outer-Membrane Cytochromes MtrC and OmcA in the Biomineralization of Ferrihydrite by Shewanella oneidensis MR-1." Geobiology 8(1):56-68.

Funding: DOE-Office of Biological and Environmental Research under the Genomics Science Program, the Subsurface Environmental Systems-Sciences Program, and the EMSL Biogeochemistry Grand Challenge

Probing the Oxygen Environment in $\mathrm{UO}_{2}{ }^{2+}$ by Solid-State O-17 NMR Spectroscopy and Relativistic Density Functional Calculations

\section{Herman Cho, ${ }^{\text {(a) }}$ Wibe A. de Jong, ${ }^{\text {(a) }}$ and Chuck Z. Soderquist ${ }^{(a)}$}

(a) PNNL, Richland, Washington

Scientists at PNNL have used state-of-the-art experimental and computational methods at EMSL to gain a deeper understanding of bonding in uranium oxides. The electronic structure of the uranyl ion $\mathrm{UO}_{2}{ }^{2+}$ was studied in two solid salts: $\left(\mathrm{NH}_{4}\right)_{4} \mathrm{UO}_{2}\left(\mathrm{CO}_{3}\right)_{3}$ and rutherfordine $\left(\mathrm{UO}_{2} \mathrm{CO}_{3}\right)$, the former representing an environment with hydrogen bonding to the uranyl oxygens. The study included an important $N M R$ "first"- the first solid-state data for $\mathrm{UO}_{2}{ }^{2+}$-and an impressive "most"- the team found 170 chemical shift anisotropies, among the largest ever reported for oxygen (>1200 ppm). For these contributions, the team's work appeared on the February 28, 2010, cover of the Journal of Chemical Physics.

To acquire and interpret $17 \mathrm{O}$ NMR spectra of the two uranyl salts, the team employed EMSL's 300-MHz Tecmag Discovery NMR spectrometer (which is adapted for radioactive samples) and the Chinook supercomputer (HP 2310-Node Linux Cluster), both of which are available to EMSL users for integrated, high-impact research that advances DOE's energy and environmental missions.

The heavy elements present the greatest challenges for theoretical understanding of molecular structure and bonding. This work examined an important uranium oxide model system through an exacting comparison of experimental NMR parameters, with results calculated by relativistic density functional computational methods, and revealed directions to 
better understanding bonding in heavy element-containing molecules. Additionally, the study marks the first solid-state NMR experiments performed on $\mathrm{UO}_{2}{ }^{2+}$. This integration of experimental and computational approaches yields a discriminating test for theoretical descriptions of covalent bonding involving a high-Z element, validates the approach, and allows extension to other compounds. It also embodies EMSL's goal to rapidly link theory and experiment.

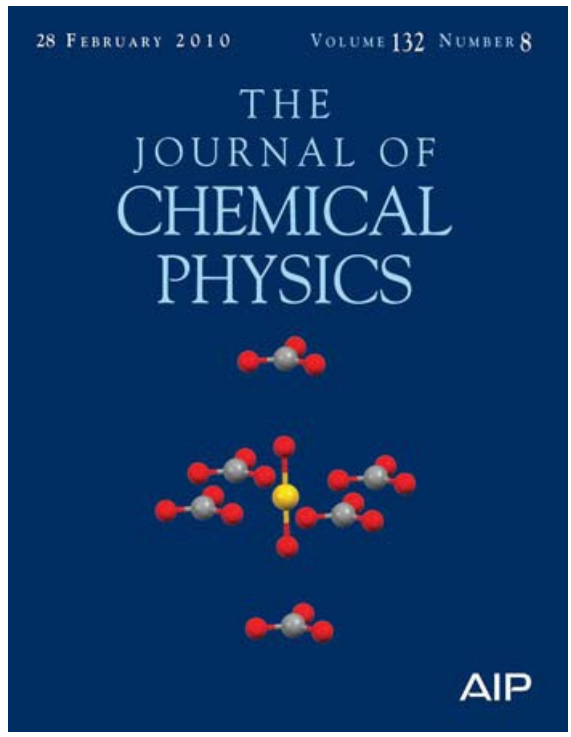

Figure 1.7. An illustration of the cluster specified in NMR parameter computations of $\mathrm{UO}_{2} \mathrm{CO}_{3}$. Atom color scheme: $\mathrm{U}=$ gold, $\mathrm{C}=$ gray, $\mathrm{O}=$ red, and $\mathrm{N}=$ blue.

This work - featured on the cover of the Journal of Chemical Physics - advances the fundamental understanding of uranium chemical interactions and makes a direct contribution to the prediction and manipulation of uranium chemistry in the environment, nuclear waste, nuclear waste processing strategies, and biological systems. Intricate knowledge of toxic materials in specific environments allows scientists and engineers to optimize strategies for the remediation of contaminated environments and safe storage of nuclear energy byproducts - protecting the health of both humans and ecosystems.

Reference: Cho HM, WA De Jong, and CZ Soderquist. 2010. "Probing the Oxygen Environment in $\mathrm{UO}_{2}{ }^{2+}$ by Solid-State O-17 NMR Spectroscopy and Relativistic Density Functional Calculations." Journal of Chemical Physics 132:084501. DOI:10.1063/1.3308499.

Funding: DOE-Office of Biological and Environmental Research

\section{Inhibition Effect of Secondary Phosphate Mineral Precipitation on Uranium Release from Contaminated Sediments}

\section{Zhenqing Shi, ${ }^{(a)}$ Chongxuan Liu, ${ }^{(a)}$ John M. Zachara, ${ }^{(a)}$ Zheming Wang, $^{(a)}$ and Baolin Deng ${ }^{(b)}$}

(a) PNNL, Richland, Washington

(b) University of Missouri-Columbia, Columbia, Missouri

Using resources and capabilities at EMSL, PNNL and the University of Missouri-Columbia scientists uncovered two reactions that suppress highly mobile uranium release to groundwater from contaminated soils. At former uranium ore mining and processing sites, highly mobile uranium lodged within soil particles can be released into groundwater during rainstorms and snowmelt. The contaminated groundwater can subsequently flow toward rivers, lakes, and other water 
sources, causing environmental health concerns. Understanding reactions that can render potential uranium sources to insoluble forms could aid in creating cost-effective remediation approaches for contaminated soils.

In a series of experiments, the scientists studied how to suppress uranium release from contaminated soils to groundwater by converting uranium from soluble to insoluble forms. They began by adding aqueous phosphate and calcium to a mixture of Hanford Site groundwater and uranium-contaminated soil. Then, with the latest in environmental spectroscopy and other techniques, they observed the formation of a calcium phosphate precipitate; uranium migration out of the original soil particles attaching to the newly formed precipitate; and conversion of the attached uranium to uranyl phosphate, which does not dissolve in typical groundwater. The phosphate concentration is crucial. At a low (1 mM) phosphate concentration, the uranium eventually resolubilizes back into the groundwater. At a high (50 mM) phosphate concentration, the uranium release was continuously suppressed.

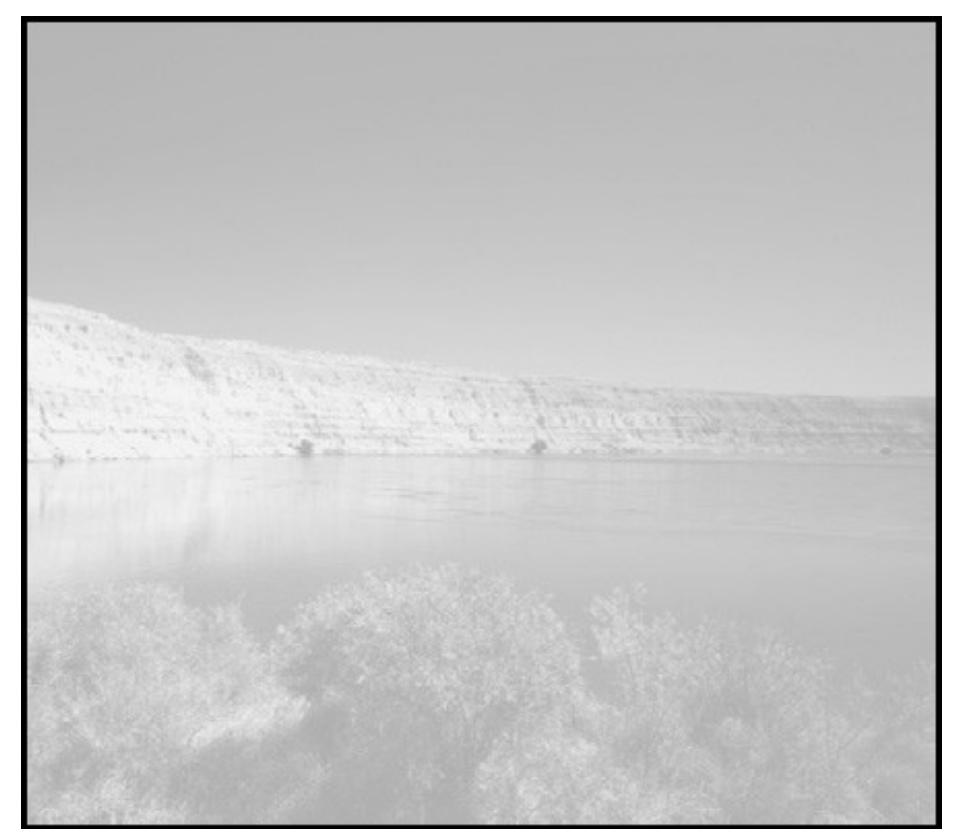

Figure 1.8. Using EMSL spectroscopy resources, scientists discovered the reactions converting uranium from soluble to insoluble forms.

This research provides mechanistic insights into how uranium can be fixed in the soil without valence state - information needed to avoid expensive trial-and-error approaches in the field.

Reference: Shi Z, C Liu, JM Zachara, Z Wang, and B Deng. 2009. "Inhibition Effect of Secondary Phosphate Mineral Precipitation on Uranium Release from Contaminated Sediments." Environmental Science and Technology 43(21):83448349.

Funding: DOE-Office of Biological and Environmental Research, Environmental Remediation Science Program 


\section{Influence of Dynamical Conditions on the reduction of U(VI) at the Magnetite-Solution Interface}

\section{Eugene S. Ilton, ${ }^{(a)}$ Jean-François Boily, ${ }^{(b)}$ Edgar C. Buck, ${ }^{(a)}$ Frances N. Skomurski, ${ }^{(a)}$ Kevin M. Rosso, ${ }^{(a)}$ Christopher L. Cahill, ${ }^{(\mathrm{c})}$ John R. Bargar, ${ }^{(\mathrm{d})}$ and Andrew R. Felmy ${ }^{(\text {a) }}$}
(a) PNNL, Richland, Washington
(b) University of Umea, Umea, Sweden
(c) George Washington University, Washington, D.C.
(d) Stanford Synchrotron Radiation Laboratory (SSRL), Menlo Park, California

In reducing the common subsurface contaminant highly soluble uranium(VI) with magnetite nanoparticles, scientists detected the pentavalent oxidation state of uranium, uranium $(V)$, despite favorable conditions for forming less soluble, less mobile, uranium(IV). The team used resources from EMSL and SSRL. This study illuminates a previously underappreciated reaction pathway for the reduction of uranium(VI). Reducing uranium to a less mobile form could be vital in controlling the radionuclide's subsurface migration.

At EMSL, the resources employed to detect uranium(V) were a combination of thermodynamic modeling, high-energy resolution monochromatic X-ray photoelectron spectrometry, and transmission electron microscopy.

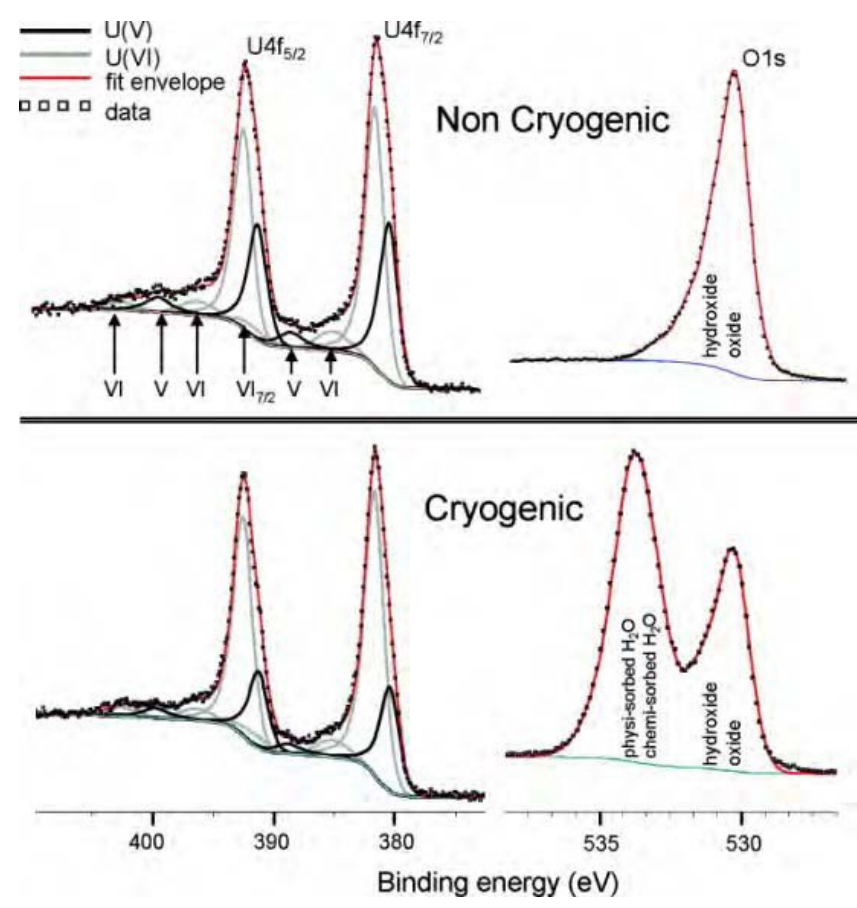

Figure 1.9. Using powerful $X$-ray photoelectron spectrometry on both cryogenic/hydrated and noncryogenic samples, scientists identified satellite structures on the spectra that indicated the presence of uranium(V).

Based on the experimental results, the team proposed a reaction pathway that involves incorporating and stabilizing uranium(V) and uranium(VI) into secondary phases. Previous studies did not consider the possibility of uranium(V) formation during the reduction of uranium(VI) by magnetite. 
The reduction of uranium(VI) in the subsurface is not completely understood. This analysis of uranium(VI) reduction to persistent uranium(V), with no evidence of reduction to uranium(IV) despite sufficient free energy to drive the reaction, shows that uranium $(\mathrm{V})$ cannot be excluded when studying reaction pathways and the attainment of redox equilibrium for uranium in environmental systems. This finding represents a significant departure from the accepted conceptual model for reduction of uranium(VI) in the subsurface.

Producing nuclear weapons in the United States made uranium the most abundant radionuclide in the subsurface at DOE facilities. Reducing uranium to a less mobile form could be vital in controlling its subsurface migration.

Reference: Ilton ES, JF Boily, EC Buck, FN Skomurski, KM Rosso, CL Cahill, JR Bargar, and AR Felmy. 2009. "Influence of Dynamical Conditions on the reduction of U(VI) at the Magnetite-Solution Interface." Environmental Science \& Technology 44(1):170-176.

Funding: DOE-Offices of Basic Energy Sciences and Office of Biological and Environmental Research Environmental Remediation Sciences Program through the PNNL Science Focus area

\subsection{Science of Interfacial Phenomena}

First Principles Simulation of the Bonding, Vibrational, and Electronic Properties of the Hydration Shells of the HighSpin $\mathrm{Fe}^{3+}$ Ion in Aqueous Solutions

\section{Stuart A. Bogatko, ${ }^{(a)}$ Eric J. Bylaska, ${ }^{(b)}$ and John H. Weare ${ }^{(a)}$}

(a) University of California, San Diego, San Diego, California

(b) PNNL, Richland, Washington

For those studying iron in water, such as in carbon sequestration, a new computer simulation supplies detailed data on $\mathrm{Fe}^{3+}$ in water. Specifically, the parameter-free, first principles simulation focuses on a high spin $3 d^{5} \mathrm{Fe}^{3+}$ hydrated in 64 water molecules. Using the molecular simulations and underlying molecular theory, the researchers predicted key ion/solution interactions. The results from these studies agreed extremely well with previous experiments conducted by other researchers. The computer code used in this study was built as part of a computationally intensive, exhaustive study by scientists from the University of California at San Diego and EMSL.

Experimental data can be used to characterize hydrated metal ions, but molecular simulations that can consistently match experimental results are needed to model ions in solution at different temperatures and pressures. Accurate computer models would speed obtaining such data. However, until now, accurate, on-the-fly representation was difficult to obtain. This new model, implemented in NWChem, accurately predicts the speciation and structure of ions in solution. This is part of EMSL's ongoing work to link theory with experiment in real time.

The interaction between iron and water is critical to reactions, including those associated with mineral formation (for example, carbon sequestration) and dissolution, contaminant transport in ground water, and activation of biochemical reactions. This model provides fundamental information about the structure and specification of iron in water, which could lead to improved understanding and eventual of control of such key reactions. This science was spotlighted on the cover of the Journal of Physical Chemistry A. 
Reference: Bogatko SA, EJ Bylaska, and JH Weare. 2010. "First Principles Simulation of the Bonding, Vibrational, and Electronic Properties of the Hydration Shells of the High-Spin $\mathrm{Fe}^{3+}$ Ion in Aqueous Solutions." Journal of Physical Chemistry A 114(5):2189-2200.

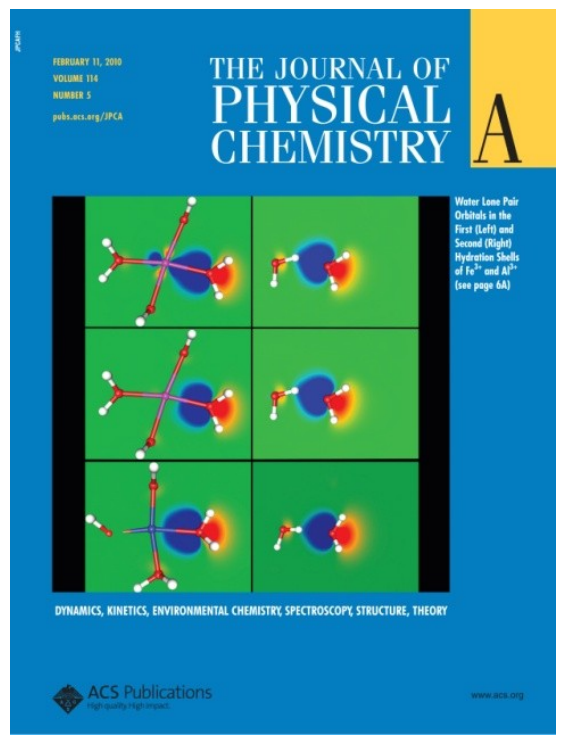

Figure 1.10. Using resources at EMSL, scientists obtained parameter-free first principles simulations of a high spin $3 d^{5}$ $\mathrm{Fe}^{3+}$ ion (colorful, larger spheres) surrounded by 64 waters (smaller red and white structures) at $30 \mathrm{ps}$ and 300 K. Cover is printed with permission of the Journal of Physical Chemistry A. (C) 2010

Funding: DOE-Office of Basic Energy Sciences and the National Science Foundation. In addition, the DOE-Office of Basic Energy Sciences funded time on the National Energy Research Scientific Computing Center at Lawrence Berkeley National Laboratory.

Extensive Regularization of the Coupled Cluster Methods Based on the Generating Functional Formalism: Application to Gas-Phase Benchmarks and to the $\mathrm{S}_{N} 2$ Reaction of $\mathrm{CHCl}_{3}$ and $\mathrm{OH}^{-}$in Water

\section{Karol Kowalski $^{(a)}$ and Marat Valiev ${ }^{(a)}$}

(a) EMSL, Richland, Washington

Whether developing new alternative energy sources or investigating the fate of environmental contaminants, scientists can now obtain precise answers about the fundamental interactions controlling these processes thanks to a predictable and robust methodology created at EMSL. The new methodology improves the accuracy of the computationally intensive approach to describing large-scale chemical systems under realistic temperatures and pressures. The computationally intensive coupled cluster approach is considered to be a key methodology in precisely describing chemical reactions. New theoretical techniques of regularization in the strong interaction regime bring this technology to the realm of practical applications. This new methodology was implemented in NWChem, a flagship computational chemistry package that runs on massively parallel supercomputers.

Using the modular structure of NWChem, the precise coupled cluster method was coupled with a molecular mechanics approach to describe chemical transformations in solutions and other complex environments. The efficiency and capability of this new method were demonstrated using several gas-phase systems. 
Precisely and efficiently, this methodology allows NWChem users to take advantage of the recently introduced theoretical developments to calculate ground state electronic energy. New theoretical formalism removes the failings of earlier methods in accounting for correlations effects and provides a precise description of chemical transformations for a wide range of practical applications, potentially including those related to contaminate removal from groundwater or the production of fuel from biowaste. This research is part of EMSL's ongoing work to develop, integrate, and deploy transformational tools capable of describing the dynamic behavior of complex systems in native environments.

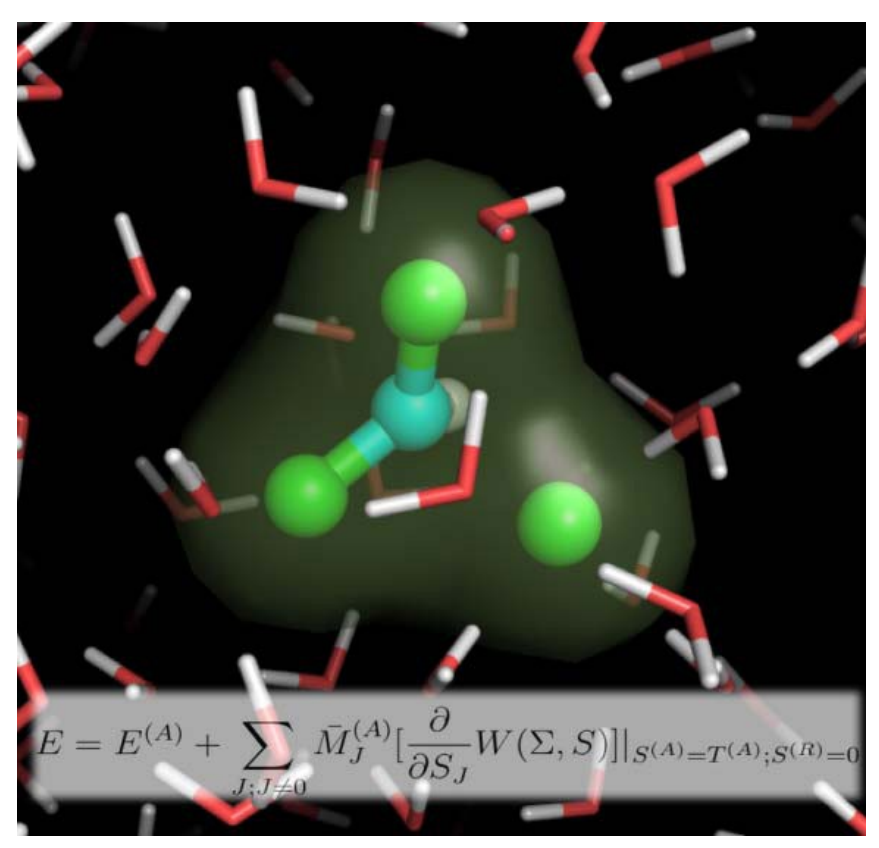

Figure 1.11. Specialists in molecular theory at EMSL achieved a breakthrough in calculating properties and behavior of molecules in chemical reactions. The new methodology is available in NWChem.

Development of new alternative clean energy sources to reduce oil dependence and avoid environmental pollution requires precise manipulations of underlying chemical transformations. To gain such a level of control requires accurate knowledge of molecular interactions that can be obtained from sophisticated computer simulations facilitated by newly developed methodology.

Reference: Kowalski K and M Valiev. 2009. "Extensive regularization of the coupled cluster methods based on the generating functional formalism: Application to gas-phase benchmarks and to the $\mathrm{S}_{\mathrm{N}} 2$ reaction of $\mathrm{CHCl}_{3}$ and $\mathrm{OH}^{-}$in water." Journal of Chemical Physics 131(23):77-88.

Funding: PNNL Laboratory Directed Research and Development, the Department of Defense Office of Naval Research, and the DOE-Office of Basic Energy Sciences 
Stabilization of Metal Nanoparticles in Cubic Mesostructured Silica and Its Application in Regenerable Deep Desulfurization of Warm Syngas

Liyu Li, ${ }^{(a)}$ David L. King, ${ }^{(a)}$ Jun Liu, ${ }^{(a)}$ Qisheng Huo, ${ }^{(a)}$ Kake Zhu,${ }^{(a)}$ Chongmin Wang,${ }^{(a)}$ Mark Gerber, ${ }^{(a)}$ Don Stevens, ${ }^{(a)}$ and Yong Wang ${ }^{(a)}$

(a) PNNL, Richland, Washington

Effective metal catalysts are vital to pollution prevention, clean energy production, and central to the interests of the DOE and the nation. Preventing nano-sized catalyst particle sintering has remained a great challenge within the field of catalysis research. PNNL researchers have intricately studied a new cubic mesostructured silica (SBA-16) catalyst support that uses its cage-like 3-D structure to protect metal and metal oxide nanoparticles, keeping them safe from heat damage. Using electron microscopy resources at EMSL, the team not only demonstrated the effectiveness of SBA-16's nanocages, but, in the process, also developed a class of SBA-16-supported regenerable metal catalysts that remove unwanted sulfur from syngas fuel.

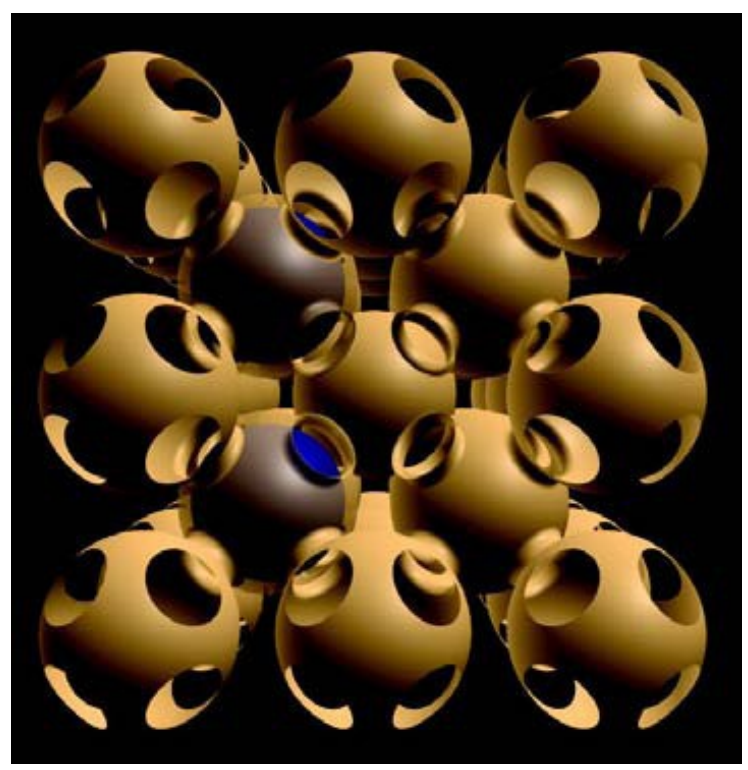

Figure 1.12. An illustration of SBA-16's spherical "cages," complete with metal nanoparticles protected within the mesostructures.

The PNNL team chose SBA-16 for its 3-D (cubic structured) advantages over other widely studied 2-D (hexagonal) supports because SBA-16 is resistant to poreblocking, allows fast transport of reactants and products, and works well at raised temperatures - features which aid efficient, less costly catalysis in real-world applications. With synthesized SBA16 , the first step was to bait its empty cages by impregnation with metal precursors (nitrate salts). After calcination and reduction, high resolution transmission electron microscopy images taken at EMSL showed that the metal nanoparticles (nickel and copper) were firmly locked inside the SBA-16 cages - free to do their catalytic work (in this case, adsorbing sulfur) without sintering and agglomerating from heat exposure. In a simulated biomass-derived syngas, the supported catalysts performed steadily through five desulfurization and regeneration cycles, showing greatly improved stability with the protection of SBA-16's nanocages. Capitalizing on the unique structure of certain supports, this "confinement strategy" should be useful in preventing nanoparticle damage or migration in a variety of other applications. 
New insights into the formation and stability of metal particles confined within nanocages gives the catalysis research community promising direction for further research and development. This work supports EMSL's goal of designing and synthesizing increasingly complex interfaces and surfaces.

Optimizing efficient, regenerable catalysts during chemical manufacturing, energy production, and automobile use can lead to enhanced removal of pollutants at lower costs — offering a future with cleaner air. In particular, syngas is produced in the gasification of biomass and helps meet the demand for cleaner transportation fuels.

Reference: Liyu L, DL King, J Liu, Q Huo, K Zhu, C Wang, M Gerber, D Stevens, and Y Wang. 2009. "Stabilization of Metal Nanoparticles in Cubic Mesostructured Silica and Its Application in Regenerable Deep Desulfurization of Warm Syngas." Chemistry of Materials 21(22):5358 - 5364. DOI: 10.1021/cm901227e.

Funding: PNNL's Laboratory Directed Research and Development Program and DOE's Biomass Energy Technology Program

\section{Using Rare Gas Permeation to Probe Methanol Diffusion near the Glass Transition Temperature}

\section{Jesper Matthiesen, ${ }^{(a)}$ R. Scott Smith, ${ }^{(a)}$ and Bruce Kay ${ }^{(a)}$}

(a) PNNL, Richland, Washington

From energy usage and storage in batteries to pharmaceutical shelf life, understanding the structure and stability of supercooled liquids and the amorphous solids they freeze into could address many open questions. Working in EMSL, scientists devised a straightforward way to diffusion in supercooled liquids. Using a layer of noble gas atoms, the PNNL scientists placed a layer of krypton or argon atoms under the liquid, which was chilled to within a few degrees of freezing solid. They then measured how fast the atoms bubbled up to surface. Using this data, they calculated the diffusion through larger or macroscopic samples. To be able to do this, they used liquid films that were only 10-100 nanometers thick. This new technique provides answers at temperatures around $100 \mathrm{~K}$ to $115 \mathrm{~K}$. Previously, the lowest temperature from which diffusion data could be obtained for methanol (studied here) was $252 \mathrm{~K}$.

Their new, straightforward approach began with the scientists putting a layer of krypton atoms under the liquid to be tested. Using molecular beam techniques at low temperatures, they covered this layer of atoms with the molecules they wanted to study. Then, they applied heat. This caused the molecules on top to start moving so the krypton atoms could bubble through the material. The researchers could not track the progress of the krypton moving around inside the material. However, using a mass spectrometer, they measured when the atoms reached the material's surface. This data was used to calculate the diffusion rate.

Reference: Matthiesen J, RS Smith, and BD Kay. 2009. "Using Rare Gas Permeation to Probe Methanol Diffusion near the Glass Transition Temperature.” Physical Review Letters 103(24):245902-1-4. DOI:

10.1103/PhysRevLett.103.245902.

Funding: DOE-Office of Basic Energy Sciences 


\section{Near-Field Localization in Plasmonic Superfocusing: A Nanoemitter on a Tip}

\section{Catalin C. Neacsu, ${ }^{(a)}$ Samuel Berweger, ${ }^{(a)}$ Robert L. Olmon, ${ }^{(a)}$ Laxmikant V. Saraf, ${ }^{(b)}$ Claus Ropers, ${ }^{(c)}$ and Markus B. Raschke ${ }^{(a)}$}

(a) University of Washington, Seattle, Washington

(b) EMSL, Richland, Washington

(c) University of Gottingen, Gottingen, Germany

Collaborating with EMSL, researchers created a true nanometer-sized light source, surpassing the diffraction limit. Under normal optical excitation, the diffraction limit prevents the focusing of light into regions smaller than several hundred nanometers in diameter. With both high brilliance and contrast, this new light source provides focused light more than one order of magnitude below the diffraction limit.

Led by Professor Raschke at the University of Washington, the scientific team converted light energy into propagating surface waves or surface plasmon polaritons on a conical tip using a special nano-fabricated grating. This grating structure was created using the focused ion beam at EMSL. As these waves propagate towards the tip, their field energy converges into the apex of the tip, creating a spatially confined intense light source. These nanometer-sized tips act as optical antennas capturing light from conventional sources and confining it to the nanoscale.

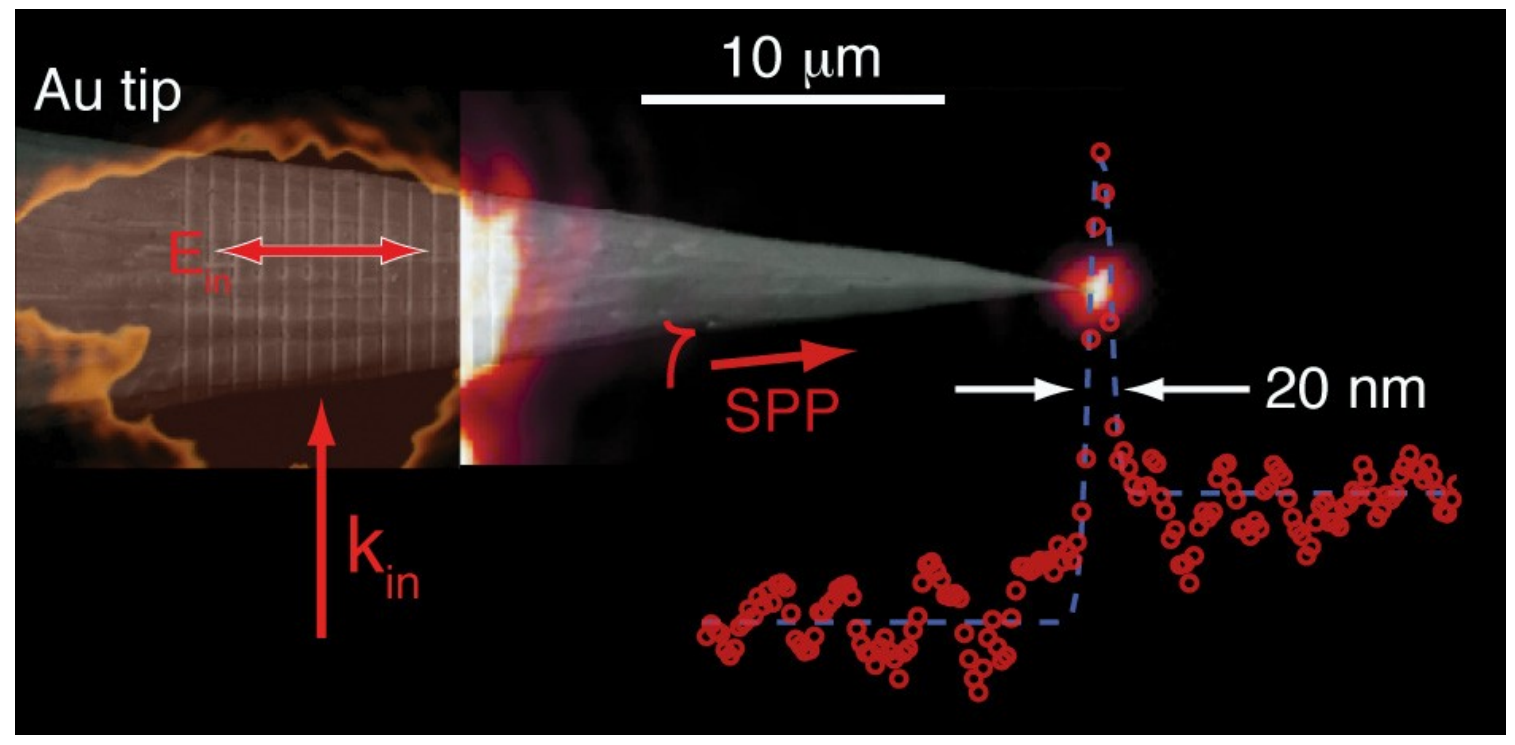

Figure 1.13. A grating, written on a gold cone using a focused ion beam, leads to surface plasmon coupling of incident laser light with near-infrared wavelength. The surface plasmon polaritons (SPP) effectively help focus the light, which, when remitted from the gold nano-tip, has a radius less than or equal to $15 \mathrm{~nm}$. The graph indicates the lateral optical scan used to measure spatial field confinement and size of the emitter at the apex. In this case, the $20 \mathrm{~nm}$ width demonstrates the highly confined light source.

This research used fundamental knowledge to design and construct a structure that enabled a significant breakthrough using surface plasmon polaritons to create an intense and highly focused light source useful for scientific studies with a range of technological applications. This is part of EMSL's efforts in designing and controlling material synthesis, which applies to EMSL's objective of materials characterization with unprecedented resolution. This research presents a novel light source with applications ranging from solar cells to medical imaging. For example, this light source could improve field-enhanced microscopy, antenna-based sensing, non-linear frequency mixing for higher harmonics generation, and 
photoelectron microscopy. In addition, it could pioneer new ways of harvesting light for photovoltaic applications. And, it could help "see" biomarkers or diseased cells in situ.

Reference: Neacsu CC, S Berweger, RL Olmon, LV Saraf, C Ropers, and MB Raschke. 2010. "Near-Field Localization in Plasmonic Superfocusing: A Nanoemitter on a Tip.” Nano Letters. DOI: 10.1021/n1903574a.

Funding: The National Science Foundation and German Excellence Initiative

Imaging Hindered Rotations of Alkoxy Species on $\mathrm{TiO}_{2}(110)$

\section{Zhenrong Zhang, ${ }^{(a)}$ Roger Rousseau, ${ }^{(a)}$ Jinlong Gong, ${ }^{(b)}$ Bruce D. Kay, ${ }^{(a)}$ and Zdenek Dohnalek ${ }^{(a)}$}

(a) PNNL, Richland, Washington

(b) University of Texas at Austin, Austin, Texas

According to a new study from PNNL and the University of Texas at Austin, hydrocarbon atoms are particular about where they want to be on a titanium dioxide catalyst. Using EMSL resources, the team conducted both experimental and theoretical studies. The catalyst's surface resembles corrugated cardboard: ridges of oxygen atoms run parallel to valleys of titanium atoms. Influenced by a weak attraction to the titanium, the hydrocarbon chain settles into the valleys. The location of the hydrocarbon chain determines, in part, how well the model catalyst titanium dioxide will perform. Understanding where the carbon chain is and why is vital data for those seeking to modify catalyzed reactions, for example, making the reactions faster or more selective.

To determine where and why the hydrocarbon chain resides on the catalyst, the team conducted both experimental and theoretical studies. The project began using EMSL's scanning tunneling microscope (STM), which provided snapshots of the catalyst's surface.

The scientists added alcohol molecules to the surface. The alcohol's oxygen atom shed its hydrogen atom and slid into a vacant oxygen spot on the catalyst's surface. To understand how the length of the chain influenced its orientation, the researchers used alcohol molecules with eight carbon atoms and varied position of the hydroxyl (-OH) anchor from the end to the middle of the hydrocarbon chain.

Using the STM, the scientists saw that the hydrocarbon chains, known as alkyl chains, had distinct preferences regarding where they resided.

Theoretical chemists used the atomic-level information from the microscopy images to perform density functional theory calculations with a van der Waals correction. The calculations showed the alkyl chains preference was based on a weak attraction between the carbon chains and the titanium atoms, as well as a slight repulsion between the carbon and the oxygen atoms. These weak attractions are known as van der Waals forces.

Further, scientists showed that the rotation of hydrocarbon chains anchored in the middle over the barrier of the oxygen rows is much harder than the rotation of hydrocarbon chains anchored at the end. This is because when the anchor is in the middle, two hydrocarbon chains have to move over the oxygens as opposed to just one.

Reference: Zhang Z, R Rousseau, J Gong, BD Kay, and Z Dohnalek. 2009. "Imaging Hindered Rotations of Alkoxy Species on $\mathrm{TiO}_{2}(110)$." Journal of the American Chemical Society 131(49):17926-17932. DOI: 10.1021/ja907431s.

Funding: DOE-Office of Basic Energy Sciences 



\subsection{Awards and Recognition}

\section{George Flynn Honored with Spectroscopy Award}

EMSL Science Advisory Committee member George W. Flynn was selected to receive the 2010 E. Bright Wilson Award in Spectroscopy from the American Chemical Society. Flynn's research into scanning tunneling microscopy and understanding molecules adsorbed on surfaces earned him this award. His students at Columbia University conduct advanced research aimed at imaging surface absorbates, including synthetic polypeptides and long-chain, chiral, functionalized hydrocarbons. Their latest work probes the structure and chemical reactivity of graphene (single sheets of graphite) on $\mathrm{SiO}_{2}$, mica, and cobalt surfaces.

As a member of EMSL's independent Science Advisory Committee, Flynn provides objective advice on long-term science direction of this national scientific user facility. This includes examining EMSL's focus on national issues, potential opportunities for transferring basic science discoveries to applications, and stewardship of the EMSL facility.

Flynn was honored at the 239th American Chemical Society national meeting in San Francisco on March 23, 2010.

To perform the coupled-cluster with perturbative triples simulation, the NWChem software relied on the PNNL-developed Global Arrays computational programming model. The software performed at 1.3 petaflops — or 1.3 quadrillion numerical operations per second — using more than 224,000 processors.

The paper describing the simulation was a finalist for the Gordon-Bell prize that recognizes outstanding achievement in high-performance computing applications.

\section{Richard Smith Honored by EMSL and Eastern Analytical Symposium}

In January 2010, EMSL user Richard D. Smith was named as the most recent Wiley Research Fellow. The program recognizes scientists who make significant contributions to EMSL outside of their individual research efforts. As a Wiley Research Fellow, Smith will contribute to EMSL's decision-making processes, including serving on advisory committees and participating on new capability proposals. In recognition of his work, he can request time on high-demand instruments normally reserved for EMSL staff.

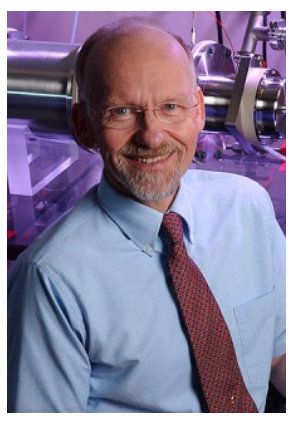

Later in the year, Smith won the 2010 Eastern Analytical Symposium Inc. award for "Excellence in the Fields of Analytical Chemistry." The award is presented to a scientist who has demonstrated significant achievements in analytical chemistry. Smith has made outstanding contributions to the analysis of complex biological samples. In particular, he was noted for his development and application of high-resolution separations and mass spectrometry methods and instruments.

A Battelle Fellow and Chief Scientist at PNNL, Smith is an internationally recognized scientific expert who has developed and applied advanced instruments for quantitative and high-throughput measurements of biological systems. Currently, he is leading PNNL's involvement in a new systems biology center for research on infectious diseases. He is a faculty member and lead investigator for the proteomics and metabolomics components of STRIDE, a center for Systems and Translational Research on Infectious Diseases. STRIDE aims to improve human health by promoting the use of systems biology approaches to better understand the complex nature of infectious disease and expedite the pace at which scientific discoveries are translated into clinical benefits. 
Smith has written or co-written more than 750 publications and book chapters. Since joining PNNL in 1976, Smith's research has garnered 36 U.S. patents and 32 foreign patents. He has received numerous honors, including eight R\&D 100 Awards, the 2003 American Chemical Society Award for Analytical Chemistry, and the 2009 Human Proteome Organization Discovery Award for Proteomics Sciences.

\section{NWChem, DOE's Premier Computational Chemistry Software, Crosses the Petaflop Barrier}

The ability to solve large scientific problems in energy, environmental, and biological sciences took a giant leap forward as EMSL's NWChem software demonstrated for the first time that it can perform at the petascale. Petascale computers are capable of performing one quadrillion—one million billion—operations per second.

"Crossing the petaflop barrier enables scientists to apply highly accurate computational chemistry methods to bigger molecular models then they could before, resulting in a better understanding of the fundamental chemical processes being studied and getting us closer to solving global challenges such as energy and environmental sustainability," said Bert de Jong, leader of NWChem software development team.

NWChem-DOE's premier computational chemistry software - crossed the petaflop barrier with a highly accurate computational chemistry simulation of a water model consisting of 24 molecules. The team of researchers from PNNL and Oak Ridge National Laboratory presented their accomplishments at the annual International Conference on HighPerformance Computing, Networking, Storage and Analysis (Supercomputing 2009) in Portland, Oregon. The simulation provides scientists with a more accurate description of water properties at the molecular level.

"Water is ubiquitous on our planet and plays an essential role in

NWCHEM HIGH-PERFORMANCE COMPUTATIONAL CHEMISTRY SOFTWARE several key chemical and biological processes," de Jong said. "Accurate models for water are crucial in understanding, controlling, and predicting the physical chemical properties of complex aqueous systems. The results obtained in this demonstration enabled us to really understand how water works. These simulations will provide definitive insights into the structure of liquid water and allow researchers to develop particular inter-molecular potentials to study more complex molecular systems." 


\section{Wendy Shaw Awarded Early Career Grant for Catalysis Research}

EMSL user and PNNL scientist Wendy Shaw received the DOE Early Career Research Program grant, which bolsters the scientific workforce by supporting exceptional researchers during their early career years when many scientists do their most formative work.

Shaw, who graduated from the University of Washington in 2000, has experience in multiple disciplines, including biology and chemistry. The grant will allow her to focus on catalysts that ultimately will enable the efficient use of renewable energy, such as solar or wind, by mimicking natural enzymes that facilitate efficient transformation between fuels and energy. While today's catalysts rely on platinum, which is rare and expensive, natural catalysts, such as hydrogenase, use nickel, iron, and other inexpensive, abundant metals.

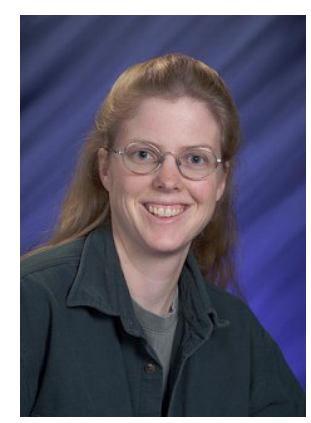

Shaw will build catalysts by developing and attaching small proteins, called peptides, to already fast nickel-based catalysts. These peptides will be specific to transporting protons to and from the active site for hydrogen production. By mimicking some of the proton transport features that enzymes use to achieve fast, efficient catalysis, the activity of these relatively simple catalysts can be enhanced to achieve similar rates to those found in nature.

In conducting this research, Shaw will collaborate with others, including Dr. David Baker at the University of Washington, researchers from the Center for Molecular Electrocatalysis, and scientists at the Institute for Interfacial Catalysis. Her work will be complemented using EMSL's computational resources. 



\subsection{Visitors and Users}

To date in Fiscal Year 2010, a total of 559 users benefited from EMSL capabilities and expertise. This total includes 389 onsite users and 170 remote users. 



\subsection{Publications}

\subsection{Books}

Hellborg R, HJ Whitlow, and Y Zhang. 2010. Ion Beams in Nanoscience and Technology. Springer, Berlin, Germany.

\subsection{Book Sections}

Adkins JN, H Mottaz, TO Metz, CK Ansong, NP Manes, RD Smith, and F Heffron. 2010. "Performing Comparative Peptidomics Analyses of Salmonella from Different Growth Conditions." In Peptidomics: Methods and Protocols, Methods in Molecular Biology, Vol 615, pp. 13-27. Humana Press, Inc., New York, New York.

Wang P and J Laskin. 2010. "Surface Modification Using Reactive Landing of Mass-Selected Ions." In Ion Beams in Nanoscience and Technology, pp. 37-65. Springer, New York, New York.

\subsection{Journal Articles}

Amonette JE, JL Barr, LM Dobeck, K Gullickson, and SJ Walsh. 2010. "Spatio-Temporal Changes in $\mathrm{CO}_{2}$ Emissions During the Second ZERT Injection, August-September 2008.” Environmental Earth Sciences 60:263-72.

Baer DR, DJ Gaspar, P Nachimuthu, SD Techane, and DG Castner. 2010, “Application of Surface Chemical Analysis Tools for Characterization of Nanoparticles.” Analytical and Bioanalytical Chemistry 396:983-1002.

Baer DR, AS Lea, J Geller, J Hammon, L Kover, MP Seah, M Suzuki, JW Watts, and J Wolstenholme. 2010. "Approaches to Analyzing Insulators with Auger Electron Spectroscopy: Update and Overview." Journal of Electron Spectroscopy and Related Phenomena 176:80-94.

Bagus PS, CJ Nelin, ES Ilton, M Baron, H Abbott, E Primorac, H Kuhlenbeck, S Shaikhutdinov, and HJ Freund. 2010. "The Complex Core Level Spectra of $\mathrm{CeO}_{2}$ : An Analysis in Terms of Atomic and Charge Transfer Effects." Chemical Physics Letters 487:237-40.

Baker ES, EA Livesay, DJ Orton, RJ Moore, WF Danielson, DC Prior, YM Ibrahim, BL Lamarche, AM Mayampurath, AA Schepmoes, DF Hopkins, K Tang, RD Smith, and ME Belov. 2010. "An LC-IMS-MS Platform Providing Increased Proteome Coverage for High-Throughput Studies.” Journal of Proteome Research 9:997-1006.

Bogatko SA, EJ Bylaska, and JH Weare. 2010. "First Principles Simulation of the Bonding, Vibrational, and Electronic Properties of the Hydration Shells of the High-Spin $\mathrm{Fe}^{3+}$ Ion in Aqueous Solutions." Journal of Physical Chemistry A 114:2189-200.

Bruns E, V Perraud, A Zelenyuk, MJ Ezell, SN Johnson, Y Yu, D Imre, BJ Finlayson-Pitts, and ML Alexander. 2010. "Comparison of FTIR and Particle Mass Spectrometry for the Measurement of Particulate Organic Nitrates." Environmental Science \& Technology 44:1056-61.

Buck EC, M Douglas, and RS Wittman. 2010. "Verifying the Presence of Low Levels of Neptunium in a Uranium Matrix with Electron Energy-Loss Spectroscopy.” Micron 41:65-70. 
Chambers SA. 2010. "Epitaxial Growth and Properties of Doped Transition Metal and Complex Oxide Films." Advanced Materials 22:219-48.

Chang CL, S Sankaranarayanan, D Ruzmetov, E Kaxiras, MH Engelhard, and S Ramanathan. 2010. "Compositional Tuning of Ultrathin Surface Oxides on Metal and Alloy Substrates Using Photons: Dynamic Simulations and Experiments." Physical Review B, Condensed Matter 81. Article No. 085406.

Cho HM, WA De Jong, and CZ Soderquist. 2010. "Probing the Oxygen Environment in $\mathrm{UO}_{2}{ }^{2+}$ by Solid-State O-17 Nuclear Magnetic Resonance Spectroscopy and Relativistic Density Functional Calculations." Journal of Chemical Physics 132:084501.

Diamond DL, AJ Syder, JM Jacobs, CM Sorensen, K-A Walters, S Proll, JE McDermott, MA Gritsenko, Q Zhang, R Zhao, TO Metz, DG Camp, KM Waters, RD Smith, CM Rice, and MG Katze. 2010. "Temporal Proteome and Lipidome Profiles Reveal HCV-Associated Reprogramming of Hepatocellular Metabolism and Bioenergetics." PLoS Pathogens 6. Article No. e1000719.

Du D, W Chen, W Zhang, D Liu, H Li, and Y Lin. 2010. "Covalent Coupling of Organophosphorus Hydrolase Loaded Quantum Dots to Carbon Nanotube/Au Nanocomposite for Enhanced Detection of Methyl Parathion.” Biosensors and Bioelectronics 25:1370-75.

Du D, M Wang, Y Qin, and Y Lin. 2010. "One-Step Electrochemical Deposition of Prussian Blue-Multiwalled Carbon Nanotube Nanocomposite Thin-Film: Preparation, Characterization and Evaluation for $\mathrm{H}_{2} \mathrm{O}_{2}$ Sensing." Journal of Materials Chemistry 20:1532-37.

Du D, Z Zou, Y Shin, J Wang, H Wu, MH Engelhard, J Liu, IA Aksay, and Y Lin. 2010. "Sensitive Immunosensor for Cancer Biomarker Based on Dual Signal Amplification Strategy of Graphene Sheets and Multi-Enzyme Functionalized Carbon Nanospheres." Analytical Chemistry 82:2989-95.

Flaud JM, WJ Lafferty, RL Sams, and VM Devi. 2010. "High Resolution Analysis of the Ethylene-1 $-{ }^{13} \mathrm{C}$ Spectrum in the 8.4-14.3 $\mu \mathrm{m}$ Region.” Journal of Molecular Spectroscopy 259:39-45.

Garten JCT, JL Smith, DD Tyler, JE Amonette, VL Bailey, DJ Brice, HF Castro, RL Graham, CA Gunderson, RC Izaurralde, PM Jardine, JD Jastrow, MK Kerley, R Matamala, MA Mayes, FB Metting, RM Miller, KK Moran, WM Post, RD Sands, CW Schadt, JR Phillips, AM Thomson, T Vugteveen, TO West, and SD Wullschleger. 2010. "Intra-Annual Changes in Biomass, Carbon, and Nitrogen Dynamics at 4-Year Old Switchgrass Field Trials in West Tennessee, USA." Agriculture, Ecosystems \& Environment 136:177-84.

Grimm F, JR Cort, and C Dahl. 2010. "DsrR, a Novel IscA-like Protein Lacking Iron- and Fe-S-Binding Functions, Involved in the Regulation of Sulfur Oxidation in Allochromatium Vinosum." Journal of Bacteriology 192:1652-61.

Ham BM, H Jayachandran, F Yang, N Jaitly, AD Polpitiya, ME Monroe, L Wang, R Zhao, SO Purvine, EA Livesay, DG Camp, SS Rossie, and RD Smith. 2010. "Novel Ser/Thr Protein Phosphatase 5 (PP5) Regulated Targets During DNA Damage Identified by Proteomics Analysis." Journal of Proteome Research 9:945-53.

Ilton ES, JF Boily, EC Buck, FN Skomurski, KM Rosso, CL Cahill, JR Bargar, and AR Felmy. 2010. "Influence of Dynamical Conditions on the Reduction of $\mathrm{U}^{\mathrm{VI}}$ at the Magnetite-Solution Interface." Environmental Science \& Technology 44:170-76. 
Jaisi DP, RE Blake, and RK Kukkadapu. 2010. "Fractionation of Oxygen Isotopes in Phosphate During Its Interactions with Iron Oxides." Geochimica et Cosmochimica Acta 74:1309-19.

Karpinets TV, A Obraztsova, Y Wang, DD Schmoyer, G Kora, BH Park, MH Serres, MF Romine, ML Land, TB Kothe, JK Fredrickson, KH Nealson, and E Uberbacher. 2010. "Conserved Synteny at the Protein Family Level Reveals Genes Underlying Shewanella Species Cold Tolerance and Predicts Their Novel Phenotypes.” Functional \& Integrative Genomics 10:97-110.

Kim J, BC Kim, D Lopez-Ferrer, K Petritis, and RD Smith. 2010. "Nanobiocatalysis for Protein Digestion in Proteomic Analysis." Proteomics 10:687-99.

Krupka KM, KJ Cantrell, HT Schaef, BW Arey, SM Heald, WJ Deutsch, and MJ Lindberg. 2010. "Characterizing Solids in Residual Wastes from Single-Shell Tanks at the Hanford Site.” Radwaste Solutions 18:64-75.

Kwak JH, JZ Hu, DW Hoyt, JA Sears, CM Wang, KM Rosso, and AR Felmy. 2010. "Metal Carbonation of Forsterite in Supercritical $\mathrm{CO}_{2}$ and $\mathrm{H}_{2} \mathrm{O}$ Using Solid State ${ }^{29} \mathrm{Si},{ }^{13} \mathrm{C}$ NMR Spectroscopy." Journal of Physical Chemistry C 114:412634.

Laskin J, A Laskin, PJ Roach, GW Slysz, GA Anderson, S Nizkorodov, DL Bones, and L Nguyen. 2010. "HighResolution Desorption Electrospray Ionization Mass Spectrometry for Chemical Characterization of Organic Aerosols." Analytical Chemistry 82:2048-58.

Laskin J, P Wang, and O Hadjar. 2010. "Soft-Landing of Co ${ }^{\mathrm{III}}\left(\right.$ Salen)+ and Mn" ${ }^{\mathrm{III}}($ Salen)+ on Self-Assembled Monolayer Surfaces." Journal of Physical Chemistry C 114:5305-11.

Levin I, CM Eakin, M-P Blanc, RE Klevit, SI Miller, and P Brzovic. 2010. "Identification of an Unconventional $E_{3}$ Binding Surface on the $\mathrm{UbcH}_{5} \sim \mathrm{Ub}$ Conjugate Recognized by a Pathogenic Bacterial $\mathrm{E}_{3}$ Ligase." Proceedings of the National Academy of Sciences of the United States of America 107:2848-53.

Li G, D Hu, G Xia, and ZC Zhang. 2010. “Catalyst Structure-Performance Relationship Identified by High-Throughput Operando Method: New Insight for Silica-Supported Vanadium Oxide for Methanol Oxidation.” Topics in Catalysis 53:40-48.

Moffet RC, TR Henn, AV Tivanski, RJ Hopkins, Y Desyaterik, AL Kilcoyne, T Tyliszczak, JD Fast, JC Barnard, V Shutthanandan, SS Cliff, KD Perry, A Laskin, and MK Gilles. 2010. "Microscopic Characterization of Carbonaceous Aerosol Particle Aging in the Outflow from Mexico City.” Atmospheric Chemistry and Physics 10:961-76.

Mott D, J Yin, MH Engelhard, R Loukrakpam, P Chang, G Miller, I-T Bae, NC Das, CM Wang, J Luo, and C-J Zhong. 2010. "From Ultrafine Thiolate-Capped Copper Nanoclusters toward Copper Sulfide Nanodiscs: A Thermally Activated Evolution Route." Chemistry of Materials 22:261-71.

Neacsu CC, S Berweger, RL Olmon, LV Saraf, C Ropers, and MB Raschke. 2010. "Near-Field Localization in Plasmonic Superfocusing: A Nanoemitter on a Tip." Nano Letters 10:592-96.

Ney A, T Kammermeier, K Ollefs, S Ye, V Ney, TC Kaspar, SA Chambers, F Wilhelm, and A Rogalev. 2010. “Anisotropic Paramagnetism of Co-Doped ZnO Epitaxial Films." Physical Review. B, Condensed Matter 81. Article No. 054420 . 
Ney A, M Opel, TC Kaspar, V Ney, S Ye, K Ollefs, T Kammermeier, S Bauer, K-W Nielsen, STB Goennenwein, MH Engelhard, S Zhou, K Potzger, J Simon, W Mader, SM Heald, JC Cezar, F Wilhelm, A Rogalev, R Gross, and SA Chambers. 2010. "Advanced Spectroscopic Synchrotron Techniques to Unravel the Intrinsic Properties of Dilute Magnetic Oxides: The Case of Co:ZnO.” New Journal of Physics 12. Article No. 013020.

Ng DC, T Song, SO Siu, C-K Siu, J Laskin, and IK Chu. 2010. "Formation, Isomerization, and Dissociation of AlphaCarbon-Centered and Pi-Centered Glycylglycyltryptophan Radical Cations." Journal of Physical Chemistry 114:2270-80.

Nguyen TB, AP Bateman, DL Bones, S Nizkorodov, J Laskin, and A Laskin. 2010. "High-Resolution Mass Spectroscopic Analysis of Secondary Organic Aerosol Generated by Ozonolysis of Isoprene.” Atmospheric Environment 44:1032-42.

Petyuk VA, W Qian, RD Smith, and DJ Smith. 2010. "Mapping Protein Abundance Patterns in the Brain Using Voxelation Combined with Liquid Chromatography and Mass Spectrometry." Methods 50:77-84.

Pierce EM, LR Reed, WJ Shaw, BP McGrail, JP Icenhower, CF Windisch, EA Cordova, and JW Broady. 2010. "Experimental Determination of the Effect of the Ratio of B/Al on Glass Dissolution Along the Nepheline $\left(\mathrm{NaAlSiO}_{4}\right)-$ Malinkoite $\left(\mathrm{NaBSiO}_{4}\right)$ Join." Geochimica et Cosmochimica Acta 74:2634-54.

Reardon CL, A Dohnalkova, P Nachimuthu, DW Kennedy, D Saffarini, BW Arey, L Shi, Z Wang, DA Moore, JS McLean, DM Moyles, MJ Marshall, JM Zachara, JK Fredrickson, and AS Beliaev. 2010. "Role of Outer-Membrane Cytochromes MtrC and OmcA in the Biomineralization of Ferrihydrite by Shewanella oneidensis MR-1." Geobiology 8:56-68.

Rosso KM, S Yanina, CA Gorski, P Larese-Casanova, and M Scherer. 2010. "Connecting Observations of Hematite $(\alpha-$ $\mathrm{Fe}_{2} \mathrm{O}_{3}$ ) Growth Catalyzed by $\mathrm{Fe}(\mathrm{II})$.” Environmental Science \& Technology 44:61-67.

Saraf LV. 2010. "Site-Specific Pt Deposition on Etching and Electrically and Thermally Isolated $\mathrm{SiO}_{2} \mathrm{Micro-Disk}$ Surfaces.” Journal of Micromechanics and Microengineering: Structures, Devices \& Systems 20. Article No. 45031.

Saraf LV, DR Baer, AS Lea, Z Zhu, JJ Strohm, SD Sitzman, and DL King. 2010. "Bulk Migration of Ni/NiO in Ni-YSZ During Reducing Conditions.” Journal of the Electrochemical Society 157:B463-B69.

Saraf LV, P Nachimuthu, MH Engelhard, and DR Baer. 2010. "Stabilization of $\mathrm{ZnMnO}_{3}$ Phase from Sol-Gel Synthesized Nitrate Precursors." Journal of Sol-Gel Science and Technology 53:141-47.

Shao Y, J Wang, MH Engelhard, CM Wang, and Y Lin. 2010. "Facile and Controllable Electrochemical Reduction of Graphene Oxide and Its Applications." Journal of Materials Chemistry 20:743-48.

Shao Y, X Wang, MH Engelhard, CM Wang, S Dai, J Liu, Z Yang, and Y Lin. 2010. "Nitrogen-Doped Mesoporous Carbon for Energy Storage in Vanadium Redox Flow Batteries.” Journal of Power Sources 195:4375-79.

Shao Y, S Zhang, R Kou, X Wang, CM Wang, S Dai, VV Viswanathan, J Liu, Y Wang, and Y Lin. 2010. "Noncovalently Functionalized Graphitic Mesoporous Carbon as a Stable Support of Pt Nanoparticles for Oxygen Reduction." Journal of Power Sources 195:1805-11.

Shvartsburg AA, K Tang, and RD Smith. 2010. "Differential Ion Mobility Separations of Peptides with Resolving Power Exceeding 50." Analytical Chemistry 82:32-35. 
Sigdel TK, A Kaushal, MA Gritsenko, AD Norbeck, W Qian, W Xiao, DG Camp, RD Smith, and MM Sarwal. 2010. "Shotgun Proteomics Identifies Proteins Specific for Acute Renal Transplant Rejection." Proteomics - Clinical Applications 4:32-47.

Smith RS, J Matthiesen, and BD Kay. 2010. "Breaking through the glass ceiling: The correlation between the selfdiffusivity in and krypton permeation through deeply supercooled liquid nanoscale methanol films." Journal of Chemical Physics 132:124502-1/10. DOI:10.1063/1.3361664.

Sperling LJ, AJ Nieuwkoop, AS Lipton, DA Berthold, and CM Rienstra. 2010. "High Resolution NMR Spectroscopy of Nanocrystalline Proteins at Ultra-High Magnetic Field.” Journal of Biomolecular NMR 46:149-55.

Tarasevich BJ, AS Lea, and WJ Shaw. 2010. "The Leucine Rich Amelogenin Protein (LRAP) Adsorbs as Monomers or Dimers onto Surfaces.” Journal of Structural Biology 169:266-76.

Uppalapati S, S Chada, MH Engelhard, and M Yan. 2010. "Photochemical Reactions of Poly(4-Vinylphenol) Thin Films." Macromolecular Chemistry and Physics 211:461-70.

Wang XB, C Chi, M Zhou, IV Kuvychko, K Seppelt, AA Popov, SH Strauss, OV Boltalina, and LS Wang. 2010. "Photoelectron Spectroscopy of $\mathrm{C}_{60} \mathrm{~F}_{\mathrm{n}}$ " and $\mathrm{C}_{60} \mathrm{~F}_{\mathrm{m}}{ }^{2-}(\mathrm{N}=17,33,35,43,45,47 ; \mathrm{m}=34,46)$ in the Gas Phase and the Generation and Characterization of $\mathrm{C}_{1}-\mathrm{C}_{60} \mathrm{~F}_{47}$ and $\mathrm{D}_{2}-\mathrm{C}_{60} \mathrm{~F}_{44}$ in Solution." Journal of Physical Chemistry A 114(4):175665. DOI: $10.1021 /$ jp9097364.

Wang XB, K Kowalski, LS Wang, and SS Xantheas. 2010. "Stepwise Hydration of the Cyanide Anion: A TemperatureControlled Photoelectron Spectroscopy and Ab Initio Computational Study of $\mathrm{CN}^{-}\left(\mathrm{H}_{2} \mathrm{O}\right)_{\mathrm{N}}(\mathrm{N}=2-5)$." Journal of Chemical Physics 132:124306/1-10.

Wang YL, HJ Zhai, L Xu, J Li, and LS Wang. 2010. "Vibrationally Resolved Photoelectron Spectroscopy of Di-Gold Carbonyl Clusters $\mathrm{Au}_{2}(\mathrm{CO})_{\mathrm{N}}{ }^{-}(\mathrm{N}=1-3)$ : Experiment and Theory." Journal of Physical Chemistry A 114(3):1247-54. DOI: 10.1021/jp903558v.

Werth CJ, C Zhang, ML Brusseau, M Oostrom, and T Baumann. 2010. "A Review of Non-Invasive Imaging Methods and Applications in Contaminant Hydrogeology Research.” Journal of Contaminant Hydrology 113:1-24.

Wiley HS. 2010. “Mind Your Manners.” The Scientist 24(1):23.

Williams KH, KP Nevin, A Franks, AL Englert, PE Long, and DR Lovley. 2010. "Electrode-Based Approach for Monitoring In Situ Microbial Activity During Subsurface Bioremediation.” Environmental Science \& Technology 44:4754.

Yao M, AG Joly, and W Chen. 2010. "Formation and Luminescence Phenomena of $\mathrm{LaF}_{3}: \mathrm{Ce}^{3+}$ Nanoparticles and Lanthanide-Organic Compounds in Dimethyl Sulfoxide." Journal of Physical Chemistry C 114(2):826-31. DOI: 10.1021/jp9092173.

Yu Z, R Devanathan, W Jiang, P Nachimuthu, V Shutthanandan, LV Saraf, CM Wang, SVNT Kuchibhatla, and S Thevuthasan. 2010. "Integrated Experimental and Modeling Study of Ionic Conductivity of Scandia-Stabilized Zirconia Thin Films.” Solid State Ionics 181:367-71. 
Zhang J, J Liu, D Wang, D Choi, LS Fifield, CM Wang, G Xia, Z Nie, Z Yang, LR Pederson, and GL Graff. 2010. "Vapor-Induced Solid-Liquid-Solid Process for Silicon-Based Nanowire Growth.” Journal of Power Sources 195:169197.

Zhang S, Y Shao, X Li, Z Nie, Y Wang, J Liu, G Yin, and Y Lin. 2010. "Low-Cost and Durable Catalyst Support for Fuel Cells: Graphite Submicronparticles.” Journal of Power Sources 195:457-60.

Zhang S, Y Shao, G Yin, and Y Lin. 2010. "Carbon Nanotubes Decorated with Pt Nanoparticles Via Electrostatic SelfAssembly: A Highly Active Oxygen Reduction Electrocatalyst.” Journal of Materials Chemistry 20:2826-30.

Zhang S, Y Shao, G Yin, and Y Lin. 2010. "Electrostatic Self-Assembly of Pt-around-Au Nanocomposite with High Activity Towards Formic Acid Oxidation." Angewandte Chemie International Edition 49:2211-14.

Zhang S, Y Shao, G Yin, and Y Lin. 2010. "Facile Synthesis of PtAu Alloy Nanoparticles with High Activity for Formic Acid Oxidation.” Journal of Power Sources 195:1103-06.

Zhang X, J Zhou, MH Chin, AA Schepmoes, VA Petyuk, KK Weitz, BO Petritis, ME Monroe, DG Camp, SA Wood, WP Melega, DJ Bigelow, DJ Smith, W Qian, and RD Smith. 2010. "Region-Specific Protein Abundance Changes in the Brain of Mptp-Induced Parkinson's Disease Mouse Model.” Journal of Proteome Research 9:1496-509.

Zhang Y, M Ishimaru, J Jagielski, W Zhang, Z Zhu, LV Saraf, W Jiang, L Thome, and WJ Weber. 2010. "Damage and Microstructure Evolution in GaN under Au Ion Irradiation.” Journal of Physics D: Applied Physics 43:085303. DOI: 10.1088/0022-3727/43/8/085303. 